\title{
Graphene-Enhanced Battery Components in Rechargeable Lithium-Ion and Lithium Metal Batteries
}

\author{
Hao-Hsun Chang ${ }^{1}$, Tseng-Hsiang $\mathrm{Ho}^{1}$ and $\mathrm{Yu}-$ Sheng Su ${ }^{2, * \mathbb{D}}$ \\ 1 Global Graphene Group, 1240 McCook Avenue, Dayton, OH 45404, USA; oliver.chang@g3-am.com (H.-H.C.); \\ shawn.ho@g3-am.com (T.-H.H.) \\ 2 International College of Semiconductor Technology, National Yang Ming Chiao Tung University, 1001 \\ University Road, Hsinchu 30010, Taiwan \\ * Correspondence: yushengsu@nycu.edu.tw
}

Citation: Chang, H.-H.; Ho, T.-H.; Su, Y.-S. Graphene-Enhanced Battery Components in Rechargeable Lithium-Ion and Lithium Metal Batteries. C 2021, 7, 65. https:// doi.org/10.3390/c7030065

Academic Editor: I. Francis Cheng

Received: 29 July 2021

Accepted: 8 September 2021

Published: 16 September 2021

Publisher's Note: MDPI stays neutral with regard to jurisdictional claims in published maps and institutional affiliations.

Copyright: () 2021 by the authors. Licensee MDPI, Basel, Switzerland. This article is an open access article distributed under the terms and conditions of the Creative Commons Attribution (CC BY) license (https:// creativecommons.org/licenses/by/ $4.0 /)$.

\begin{abstract}
Stepping into the 21st century, "graphene fever" swept the world due to the discovery of graphene, made of single-layer carbon atoms with a hexagonal lattice. This wonder material displays impressive material properties, such as its electrical conductivity, thermal conductivity, and mechanical strength, and it also possesses unique optical and magnetic properties. Many researchers see graphene as a game changer for boosting the performance of various applications. Emerging consumer electronics and electric vehicle technologies require advanced battery systems to enhance their portability and driving range, respectively. Therefore, graphene seems to be a great candidate material for application in high-energy-density/high-power-density batteries. The "graphene battery", combining two Nobel Prize-winning concepts, is also frequently mentioned in the news and articles all over the world. This review paper introduces how graphene can be adopted in Li-ion/Li metal battery components, the designs of graphene-enhanced battery materials, and the role of graphene in different battery applications.
\end{abstract}

Keywords: graphene; composite; energy storage; battery; anode; cathode; separator; current collector

\section{Introduction}

Graphene, a one-atom-thick, 2D carbon material, was first discovered in the early 2000s [1,2]. Due to graphene's overwhelming performance advantages regarding its electrical, thermal, mechanical, optical, and magnetic properties, it drew tremendous attention from researchers in many different fields. A considerable number of application developers tried to utilize graphene to boost performance in their devices, including that of battery applications. Figure 1 shows the number of academic publications related to graphene and lithium batteries (lithium-ion and lithium metal batteries) after 2000. In fact, both fields had the same growing trend of publication number, exhibiting an explosive growth of research interest in graphene- and lithium-based battery technologies in recent years. It is clear to see that graphene studies started to substantially increase right after the Nobel Prize in Physics was awarded in 2010 [3]. The lithium battery research field also displayed a similar rise in its publication number over the last decade, exhibiting its popularity due to the public's desire for a better battery. The pioneers who developed lithium-ion batteries also won the 2019 Nobel Prize in Chemistry [4]. In 2018, more than $25 \%$ of lithium battery publications were related to graphene. Using graphene has benefits in advancing battery material performance. In industry, the mainstream applications of lithium-ion batteries gradually shifted from cell phones and portable consumer electronics to transportation and grid storage applications. These novel applications strongly rely on the advancement of battery technologies to expand their capability for more features and a longer operation time, and graphene technologies always remain under consideration for use in next-generation batteries. 
Graphene

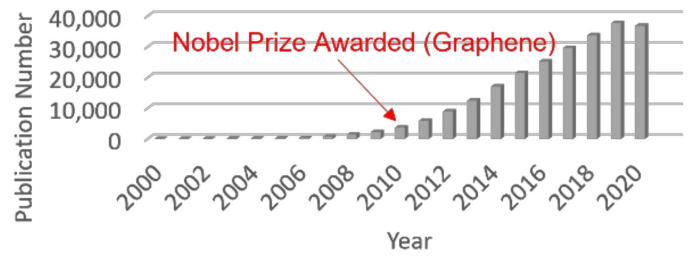

Lithium Battery

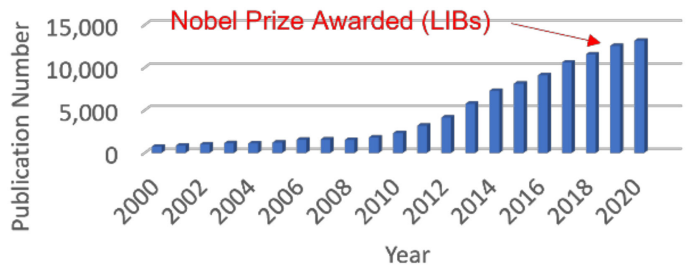

Graphene + Lithium Battery

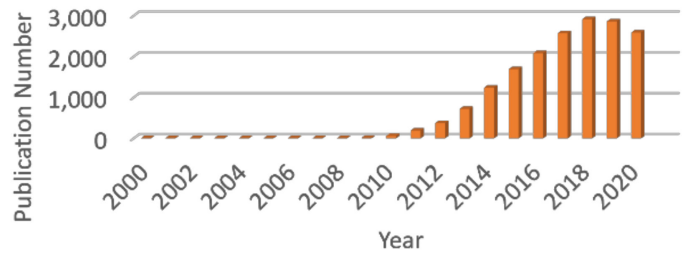

Figure 1. The number of academic publications by year using the keywords graphene (up), lithium battery (middle), and graphene + lithium battery (bottom) (source: Web of Knowledge, 18 May 2021).

The development of battery technology is relatively slower than that of other technologies because the material selections of battery components are limited. As anode or cathode materials are present in rechargeable lithium-ion batteries, they need to be active within a certain voltage window to insert or extract lithium ions, and their structures need to be stable after hundreds or even thousands of charge/discharge cycles $[5,6]$. Current conventional graphite anode materials and lithium cobalt oxide materials, which were developed in the early 1990s [7], still exist in major smart phone battery applications. This shows how difficult it is to replace battery materials even after extensive developments over three decades. Electrochemically inactive battery components, such as separators and current collectors, are also important for battery performance. Although separators and current collectors are not active materials in electrochemical reactions, appropriate graphene modifications can still improve their safety features, cycle life, and the power density of the battery [8,9]. In this review, we introduce the structural designs/processing methods of graphene-enhanced battery components and share the recent developments of graphene applications in anodes, cathodes, separators, and current collectors.

\section{Designs and Methods of Integrating Graphene into Battery Components}

As a wonder material, graphene possesses many unique properties [10-13]. The thinnest known material can modify coated material without increasing it too much in thickness. Graphene is also the strongest material ever measured, making it an excellent candidate to reinforce the mechanical strength of composite materials. Moreover, the ultrahigh electrical and thermal conductivities in two dimensions are the most adopted properties in practical applications. Graphene can sustain current densities six orders of magnitude higher than that of copper [10]. Record heat transfer capability means graphene is frequently used in thermal dissipation and cooling applications. The impermeability of graphene also expands its use for sealing and anti-leakage purposes. Graphene's extremely large surface area facilitates absorption, including that of liquids, ions, molecules, etc. [12,14]. In addition, the hydrophobicity of graphene can be utilized to enable water- 
resistant and self-cleaning functions [13]. The chemical inertness of graphene makes it a great anti-corrosion coating material as well [13]. Researchers have been employing these impressive characteristics of graphene to boost battery component performance via smart designs and synthesis methods. In this review paper, the cases of graphene serving as an active material in batteries will not be discussed, and the topics of focus are more related to graphene as a performance booster (coatings, additives, minor ingredients in composites, etc.) for battery components.

There are many ways to integrate graphene into battery components. The main idea is to make sure graphene can be well dispersed in the composite material, so a homogeneous structure of the multi-phase material can be obtained. Figure 2 summarizes a few typical structural designs of graphene composites [15,16].

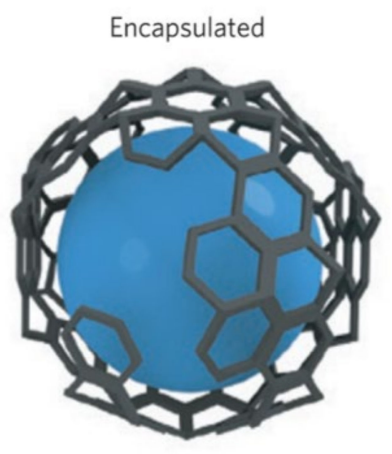

Anchored

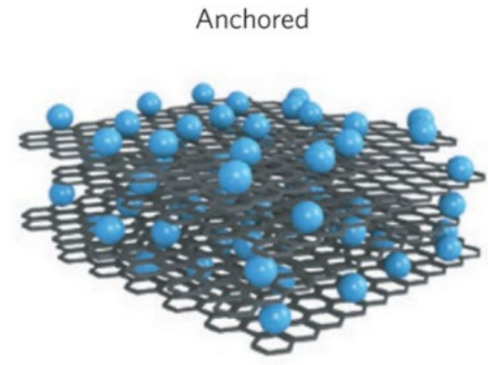

Mixed

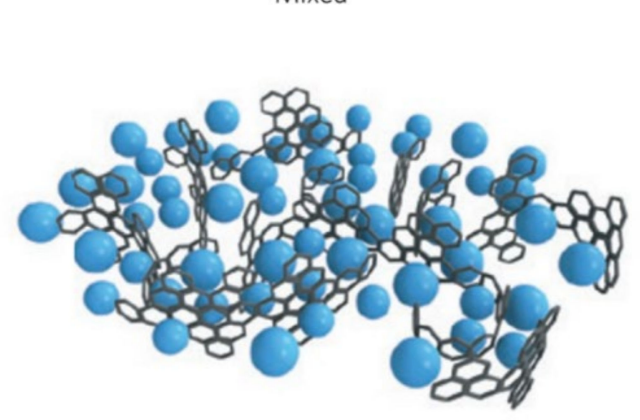

Layered

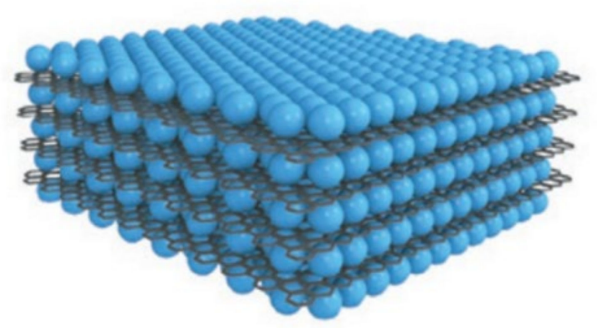

Figure 2. Schematic drawings of graphene composite materials with various structures. Reproduced with permission from ref. [16]. Copyright 2015, Elsevier.

The encapsulated type shows that graphene fully wraps the composite material particle. This can change the surface property of original particles and ensure excellent graphene dispersibility. Due to the large surface area of graphene, the quantity of graphene added does not necessarily need to be large. In addition, the encapsulated design can introduce void space into the structure, which is critical to buffer the expansion of certain electrode materials. However, voids in the battery composite materials will reduce the volumetric energy density and power density, so a balance between energy density, powder density, volume change, and cycle life must be considered. To synthesize this type of composite material, solid-state processing may not guarantee a good dispersion, thus liquidstate dispersing methods followed by specific particle granulating/atomizing/drying processes could be a better choice [17].

The mixed type is a random distribution of graphene within the composite material. Unlike the encapsulated type, there might be an agglomeration of graphene sheets or composite particles in the mixed type, which could degrade the graphene performance and efficacy. However, the preparation of mixed-type graphene composite materials should have a much lower cost if simple solid-state or liquid-state mixing methods are used. This design can be used for cost-sensitive applications [18].

The anchored design is usually used when the composite material is synthesized using graphene as the substrate. Large-surface-area graphene sheets can serve as good 
seeding planes for the composite material to precipitate and grow. During the synthesis process, the homogeneous dispersion between graphene and the composite material can be maintained if the nucleating and growing mechanisms are concentration controlled. In the initial stage of synthesis, the graphene sheets have to be deagglomerated to avoid graphene re-stacking and therefore lower the usage of graphene $[19,20]$.

The layered design is majorly employed in structures with a flat surface, such as thin-film electrodes, separators, and current collectors. The thin coating of graphene can significantly improve the electrical/thermal/mechanical/optical properties and anticorrosion behavior of the coated material. Layer-by-layer methods can be applied to make sandwiched or multi-layer structures considering application requirements. Chemical vapor deposition (CVD) is a powerful method to make a continuous graphene coating on the surface but requires vacuum environments, which bring up concerns of scalability. Using a graphene dispersion to coat the material surface can be cost-effective, but this may introduce defects located in the overlapping areas of smaller graphene sheets [21-24].

There have been many synthetic methods developed to incorporate graphene in composite materials $[17,20,22,25,26]$. Nevertheless, some of the manufacturing processes can only be carried out in a lab and are questionable in terms of scaling up [25-28]. The precursor of graphene materials can be in gas phase using the CVD process (bottom-up) or bulk/powdery graphite materials using the exfoliation process (top-down). The CVD technique can make defect-free graphene perfectly deposited on the flat substrate, but it is not suitable for making powdery composite materials such as battery anode and cathode materials. On the other hand, CVD processing is widely adopted in the semiconductor industry since the chip making cost is based on the calculation of each microchip occupying only a tiny area, which is affordable since the amount of coating materials used is small. On the contrary, powdery materials possess a much larger surface area compared to that of microchips, indicating a much larger amount of coating materials used. The powder also needs to be agitated during processing, otherwise it will lead to an inhomogeneous graphene coating. This will make the CVD graphene coating process more complicated and significantly increase the manufacturing cost because the powdery materials are always priced by weight, not area, which makes CVD an unfavorable manufacturing method for graphene composite electrode materials $[29,30]$.

Therefore, the strategy of using bulk graphite as the starting material looks like a feasible means to realize scalable synthesis. Here, we summarize a few scalable synthetic routes in Figure 3. There are at least three routes to obtain graphene sheets directly from the graphite.

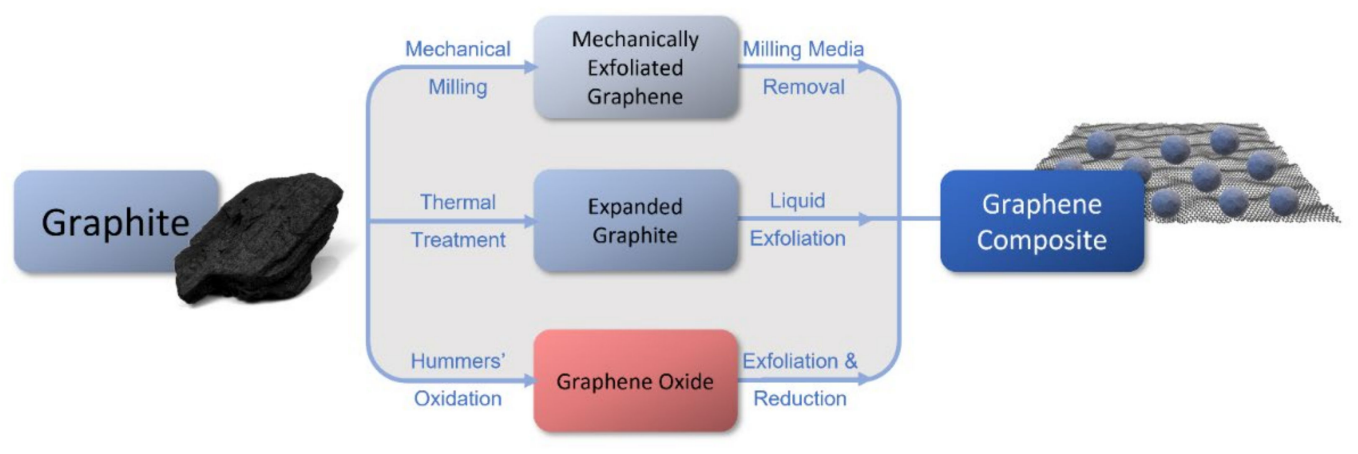

Figure 3. Scalable synthetic routes of graphene-composite materials.

First, high-energy mechanical milling can be adopted to exfoliate graphite [31]. The shear force along the 2D directions can delaminate graphene sheets, although single-layer graphene is still difficult to obtain in this way. Adding the composite material into the milling container will initiate the graphene coating process. With appropriate milling time and energy, the graphene sheets will then attach to the surface of the composite material. The only post-process would be the removal of milling media. This method is suitable for 
making mixed-type graphene composites, which is very simple, easy to scale up, and lowcost in terms of raw material and processing. Some drawbacks of mechanically exfoliated graphene are (1) the quality of graphene sheets could be inconsistent due to mixing up of single-layer and multi-layer graphene, (2) the binding force between graphene sheets and the composite material could be weak, (3) both the particle size of the composite material and the lateral flake size of graphene will be reduced, and (4) defects and impurities could be introduced during the high-energy milling process.

Second, graphite after proper thermal treatments will transform into expanded graphite. Graphite in an expanded state is much easier to exfoliate in solvents by sonicationassisted, surfactant-assisted, or polymer-assisted liquid-phase exfoliation [32]. After a welldispersed graphene solution has been made, the composite material will then be added into the bath for the incorporation process. Anchored-type graphene composite materials can be synthesized using this method by precipitating active materials onto the graphene sheets after the exfoliation process in the solution. This method shares the same concern as graphene prepared by mechanical milling, where the binding force will not be strong without further treatments. Another disadvantage is that the yield of single-layer graphene could be relatively low, even though it can be classified in the liquid-phase dispersion state.

Third, graphite can be oxidized by employing Hummers' method [33]. The oxygen located in the interlayer between graphene oxide (GO) sheets can assist the segregation of graphene layers in solvents [34]. The oxygen group on the surface can also serve as the functional group to avoid graphene re-stacking and create a bonding with the composite material. This feature facilitates the combination between graphene oxides and composite materials due to their function group interactions, which is favorable for the synthesis of encapsulated-type or layered-type composites. There is a post-reduction process to obtain graphene in the composite by either the thermal reduction method or chemical reduction methods. The composite materials might be impacted by thermal or chemical treatments, thereby limiting their applicability [35-37]. Incomplete GO reduction will also deteriorate the conductivity of the as-synthesized graphene. The shortcomings of utilizing GO are (1) strong oxidants are employed, which are not environmentally friendly, and (2) many defects could be created during the oxidation reaction.

\section{Graphene-Enhanced Anode Materials}

Graphite-based anode materials have been used for a long time in lithium-ion batteries. Due to their lithium-ion intercalation capability, graphite anodes exhibit highly efficient lithium-ion storage performance with excellent reversibility during charge/discharge [38]. A solid electrolyte interface (SEI) layer is formed on the surface of graphite during lithiation, which not only suppresses the co-intercalation of electrolyte solvents into the layered interspace in between the graphitic honeycomb lattice but also passivates the active graphite surface to avoid continuous electrolyte decomposition [39]. However, the specific capacity of commercial graphite anodes has already reached its theoretical limit $\left(372 \mathrm{~mA} \mathrm{~h} \mathrm{~g}^{-1}\right)$. To develop an advanced high-energy-density lithium-ion battery, replacing graphite with a high-capacity anode material is inevitable. Utilizing graphene to decorate novel anode materials can improve electrical conductivity, stabilize interfacial reactions, and maintain structural integrity.

\subsection{Graphene-Enhanced Alloy-Type Anode Materials}

Alloy-type anode materials are promising candidates for next-generation lithium-ion batteries because of their high specific capacity and safety characteristics [40]. Most alloytype anode materials can take multiple lithium-ions per atom during the lithiation process. Silicon attracted a lot of attention due to its high theoretical capacity $\left(4200 \mathrm{~mA} \mathrm{~h} \mathrm{~g}^{-1}\right.$ calculated based on the final product $\mathrm{Li}_{4.4} \mathrm{Si}$ ) and abundance on Earth. Nevertheless, silicon is a semiconductor, requiring conductive additives, usually carbon-based materials, to ensure low resistance for smooth electrochemical reactions [41]. While silicon is lithiated and transformed into $\mathrm{Li}_{4.4} \mathrm{Si}$ alloy, the volume expansion is huge $(320 \%)$ and therefore leads 
to particle pulverization [40,42]. This swelling behavior will result in not only gap formation within the crack area, which substantially increases the internal resistance, but also SEI reformation during repeated cycles that consumes excess active lithium ions $[41,43,44]$. From the perspective of electrodes, the irregular volume expansion could induce electrode delamination and thereby kill the battery. Many researchers have spent much time and effort using graphene to tackle the aforementioned challenges [41,45-58].

Luo et al. prepared an aqueous GO and silicon nanoparticle dispersion first, and then used an ultrasonic atomizer to create a mist of aerosol droplets, which passed through the tube furnace for the following drying and heat reduction processes [56]. The aerosol droplets shrank during drying and formed denser crumpled graphene balls with silicon particles inside after reduction (Figure 4a). In Figure 4b, the Si@crumpled graphene anode material gave much better initial Coulombic efficiency (ICE) and cycling Coulombic efficiency than the bare silicon nanoparticles for the first 20 cycles, resulting from the anode surface protection of graphene. Without the surface stabilization enabled by graphene, the SEI grown on the silicon nanoparticles will repeatedly fracture and rebuild cycle by cycle, consuming a lot of lithium ions and electrolyte and generating a very thick and poorly conductive SEI layer. Figure 4c exhibits the poor cycle life of the unprotected bare silicon nanoparticles originating from the SEI overgrowth. In contrast, the Si@crumpled graphene anode outperformed the pristine silicon anode in cycling reversibility due to the surface stabilization enabled by graphene.

(a)

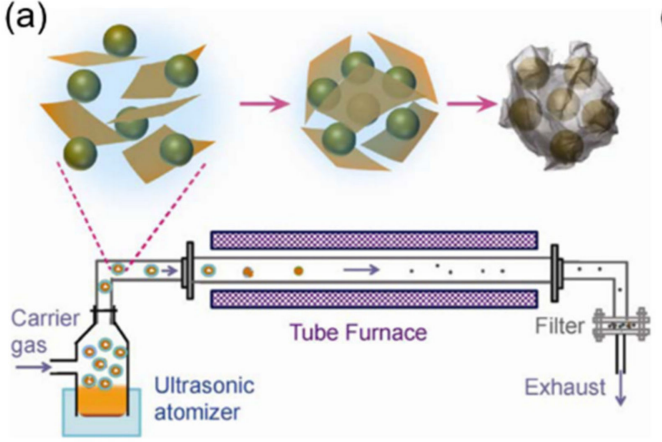

(b)

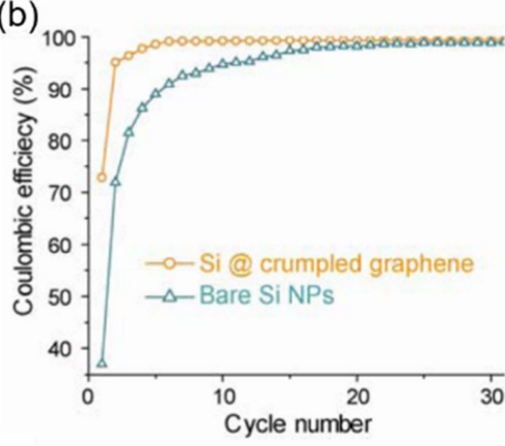

(c)

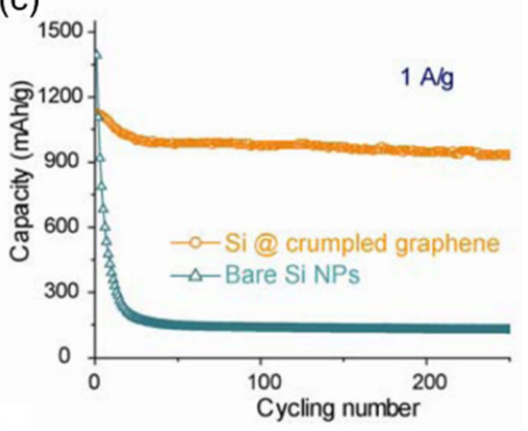

Figure 4. (a) Schematic drawing illustrating the synthesis of the crumpled-graphene-wrapped Si nanoparticles. (b) Coulombic efficiency of the Si@crumpled graphene compared to the bare Si nanoparticles. (c) Charge/discharge cycling data of the Si@crumpled graphene compared to the bare Si nanoparticles. Reproduced with permission from ref. [56]. Copyright 2012, ACS Publications.

Li et al. utilized silicon microparticles as the anode material, which has well-known disadvantages such as structural pulverization and uncontrolled SEI growth after lithiation, as shown in Figure 5a [42,50]. This is the classic failure mechanism of micron-sized silicon anode materials generating inactive silicon clusters after cycling. The authors developed a mechanically flexible graphene cage to accommodate the silicon microparticles with reserved void space (Figure $5 b$ ). Although the lithiated silicon microparticles still fractured, the pulverized particles were confined within the conformal graphene cage. Thus, the electrical contact of active silicon was retained, and the SEI only grew onto the surface of graphene. The defects located on the graphene cage served as lithium-ion pathways, which were sealed by the thin SEI after cycling. Figure $5 c, d$ compare the mechanical strength between the amorphous carbon shell and the graphene cage. It is clear to see that the amorphous carbon was broken after pressure was applied by a tungsten tip. On the contrary, the graphene cage showed an outstanding flexibility under the same pressure, which could recover its original shape after the pressure was released. The flexible graphene cage demonstration was solid proof for accommodating the volume expansion of silicon and other alloy-type anode materials. 
(a)

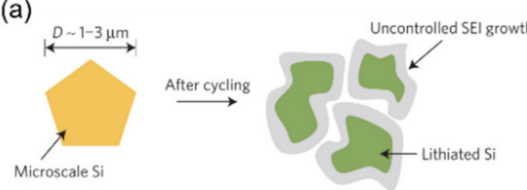

(b)

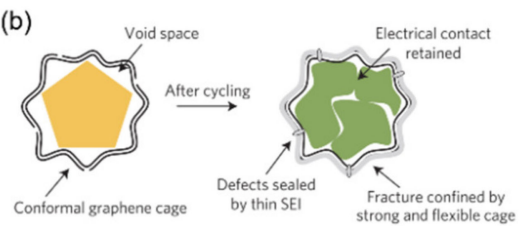

(c)
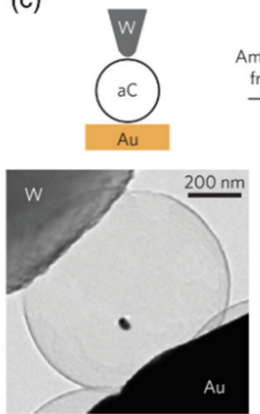

(d)

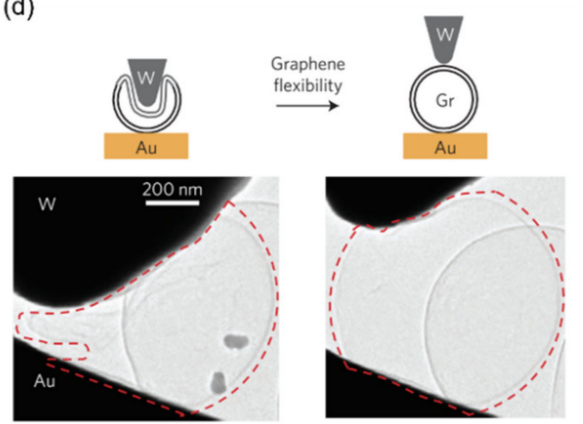

Figure 5. (a) The failure mechanism of Si microparticles in the anode during repeated battery cycling. (b) Enhanced structural stability and SEI control of Si microparticles with a mechanically flexible graphene cage. (c) Schematic and real-time TEM images of applying pressure to the empty shell of amorphous carbon. (d) Schematic and real-time TEM images of applying pressure to the graphene cage. Reproduced with permission from ref. [50,59]. Copyright 2017, ACS Publications. Copyright 2016, Nature Publishing Group.

Other group IV elements such as germanium and tin are also good alloy-type anode materials [60-67]. Mo et al. designed a 3D N-doped graphene foam to encapsulate germanium particles exhibited in Figure 6a [60]. Internal void space was included to create the yolk-shell structure. Extra void space can buffer the volume expansion when germanium is alloyed with lithium, so the secondary particle size was controlled. Nevertheless, if the density of anode particles is too low, high volumetric energy density may not be achieved. The gap between the internal active material and graphene could also lead to poor conductivity, which can influence the rate capability. It was reported that the nitrogen doping in graphene can improve its reversible capacity of lithium storage and increase the wettability of electrodes in electrolytes [68]. Figure $6 \mathrm{~b}$ compares the rate performance of various germanium anode designs. The graphene yolk-shell nanoarchitecture (Ge-QD@NG/NGF/PDMS) outperformed the other two samples and showed excellent high-rate performance and cycling stability. With the 3D N-doped graphene foam structure, the germanium anode delivered a capacity of over $800 \mathrm{~mA} \mathrm{~h} \mathrm{~g}^{-1}$ at $40 \mathrm{C}$ (charge/discharge within $90 \mathrm{~s}$ ) without capacity degradation. The graphene framework can promote fast charge transfer and ensure smooth electrochemical reactions even under high current density.

Qin et al. used graphene to coat tin nanoparticles to make the core-shell structure, and built an external 3D graphene network to accommodate the graphene-Sn composite anode material (Figure 6c) [64]. The graphene shell can guarantee good electronic pathways, and the external 3D graphene network can provide abundant space for the active tin to freely expand during lithiation, thereby stabilizing the electrochemical reactions. Figure $6 \mathrm{~d}$ compares the cycle performance of different tin anodes, and the one with the graphene network structure (3D Sn@G-PGNWs) shows the best performance among all in terms of specific capacity $\left(>1000 \mathrm{~mA} \mathrm{~h} \mathrm{~g}^{-1}\right)$ and capacity retention. 


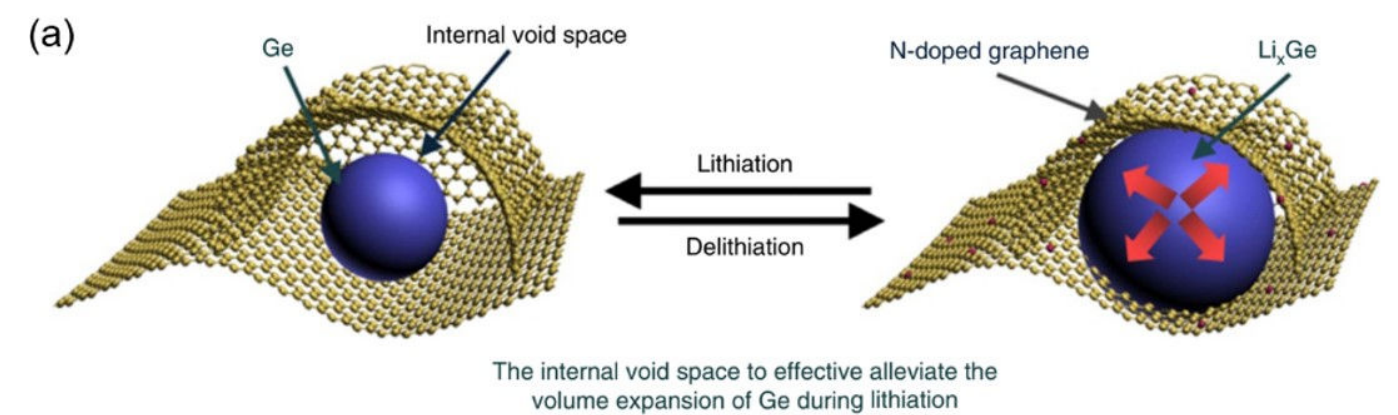

(b)

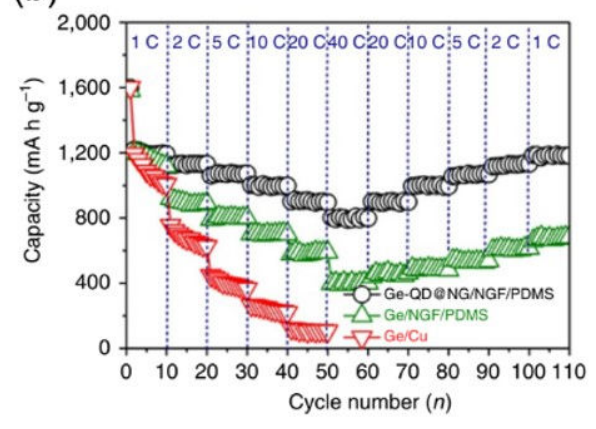

(c)

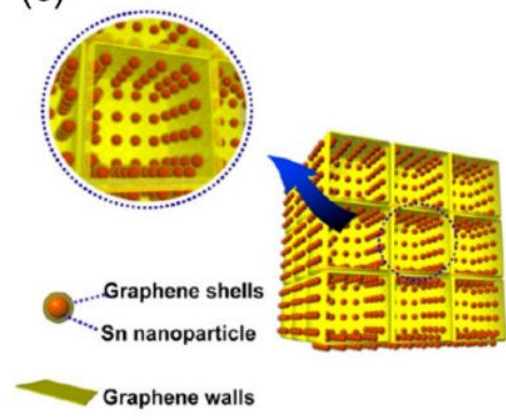

(d)

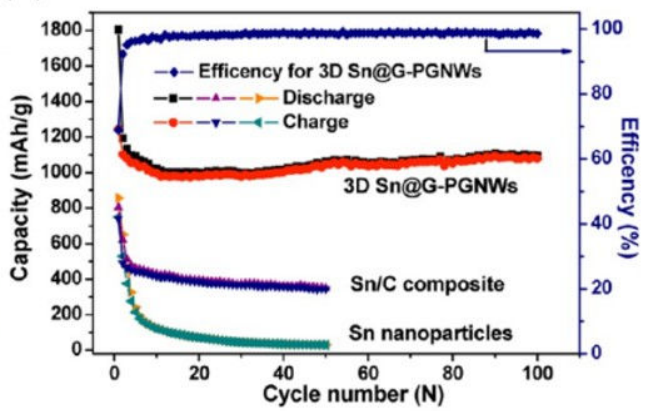

Figure 6. (a) Schematic drawing of the lithiation/delithiation process of the graphene-Ge yolk-shell composite anode material. (b) Rate performance of the graphene-Ge yolk-shell composite anode material. Reproduced with permission from ref. [60]. Copyright 2017, Nature Publishing Group. (c) Schematic drawing of the graphene-Sn composite anode material in the 3D graphene network. (d) Cycle performance of the graphene-Sn composite anode material in the 3D graphene network. Reproduced with permission from ref. [64]. Copyright 2014, ACS Publications.

\subsection{Graphene-Enhanced Conversion-Type Anode Materials}

Besides alloy-type anode materials, there are conversion-type anodes that can also deliver high specific capacity in lithium-ion batteries, originating from the multi-ion lithiation of metal compounds $\left(\mathrm{M}_{\mathrm{a}} \mathrm{X}_{\mathrm{b}}\right)$ [69]. Similar to alloy-type anodes, conversion-type anodes also suffer from the disadvantage of particle pulverization during charge and discharge cycles. The major difference between conversion-type and alloy-type anodes is that the metal ions in conversion-type anodes will be reduced to element metal, and the anions will undergo the lithiation process, which will then form multiple phases (metal particles along with lithium oxide/sulfide) in the structure. The boundary located at the interface of two different phases may create defects, which would be the cracking points when the internal stress accumulates during lithiation/delithiation. Lithium oxide and lithium sulfide can serve as adequate lithium-ion conductors in the structure, but they are electrical insulators with a very high resistance. One challenge of conversion-type anode materials is that their intrinsic electrical and ionic conductivity are both poor [69], where the incorporation of graphene can be very helpful.

Figure 7 shows the battery performance comparisons of several oxide-based conversion anode materials with appropriate designs of graphene decoration/modifications. Cobalt oxides [70,71], iron oxides [72-74], nickel oxides [75], copper oxides [76,77], manganese oxides [78,79], zinc oxides [80], and tin oxides [81,82] all have better specific capacity than that of graphite anodes while they form composites with graphene. Graphene can retain the structural change even if the active material pulverizes. Most of the grapheneenhanced metal oxide anode materials exhibit much lower electrochemical impedance than that of the pristine ones. As a result, graphene/metal oxide composite materials have greater active material utilization, better rate performance, and a longer cycle life compared to the graphene-free counterparts. 
(a)
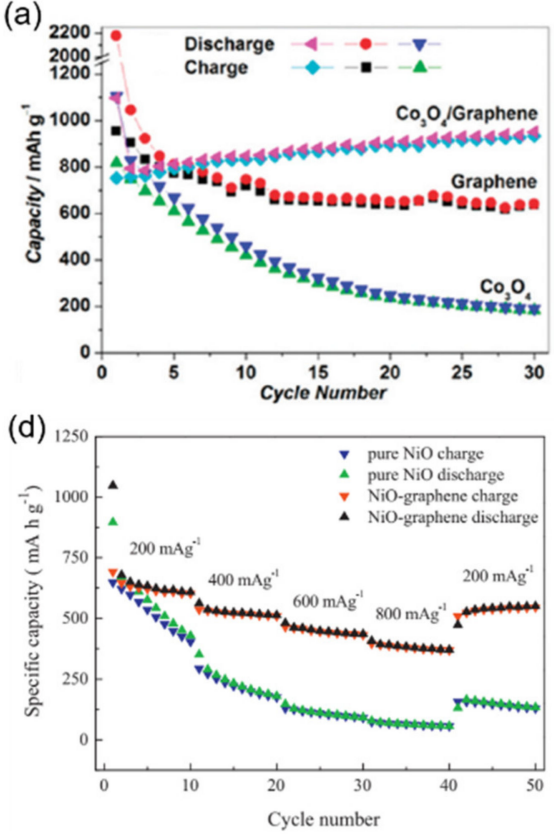

(b)

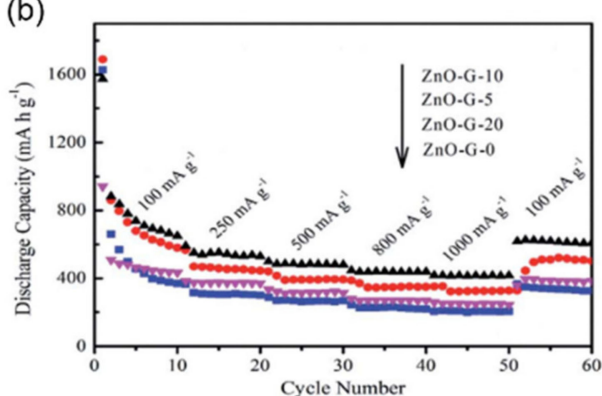

$(\mathrm{e})$

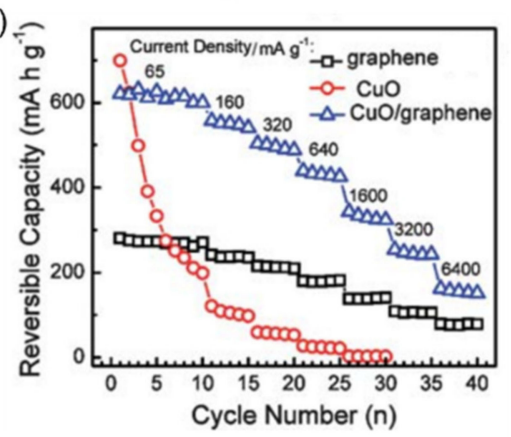

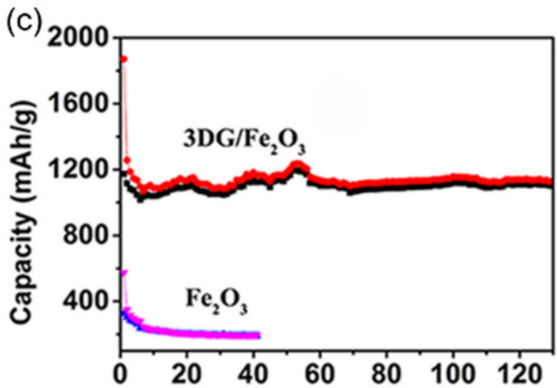

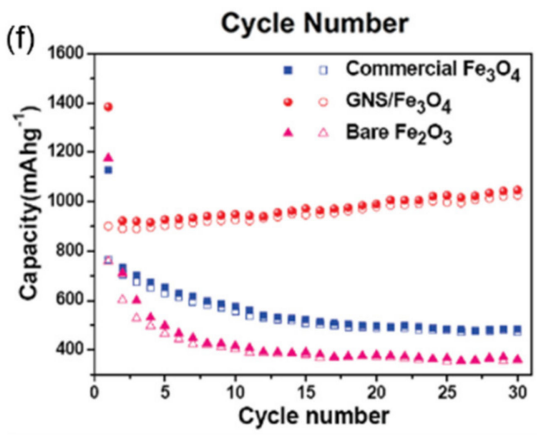

Figure 7. Cycle performance of graphene composite anode materials with (a) $\mathrm{Co}_{3} \mathrm{O} 4$, (b) $\mathrm{ZnO}$, (c) $\mathrm{Fe}_{2} \mathrm{O}_{3}$, (d) $\mathrm{NiO},(\mathbf{e}) \mathrm{CuO}$, and (f) $\mathrm{Fe}_{3} \mathrm{O}_{4}$. Reproduced with permission from ref. [71-73,75,76,80], respectively. Copyright 2010, ACS Publications. Copyright 2014, the Royal Society of Chemistry. Copyright 2017, ACS Publications. Copyright 2011, Elsevier. Copyright 2010, the Royal Society of Chemistry. Copyright 2010, ACS Publications.

The same improvements can also be found in metal sulfide anode materials after graphene modifications [83-90]. Figure 8 exhibits several conversion-type metal sulfidebased anode materials, and they all show better specific capacity, rate capability, and cycle stability with the assistance of graphene materials. Much lower impedance was observed in the graphene/metal sulfide composite materials during cycling, leading to smooth electrochemical reactions and good lithium-ion storage capability in these anodes. However, a concern of conversion-type metal sulfide anode materials is that the lithiated product, lithium sulfide $\left(\mathrm{Li}_{2} \mathrm{~S}\right)$, is highly reactive with the moisture in the air. The unwanted reaction will generate toxic hydrogen sulfide $\left(\mathrm{H}_{2} \mathrm{~S}\right)$ gas, which is lethal even when just inhaling a small quantity of it. This will raise some safety concerns when using sulfide-type anode materials and must be addressed before widespread commercialization.

The graphene-enhanced conversion-type anode materials possess high reversible capacity, safe operating voltages, and multiple choices of compositional designs. However, the low ICE issue has remained since the formation of $\mathrm{Li}_{2} \mathrm{O}$ and $\mathrm{Li}_{2} \mathrm{~S}$ may not be fully reversible. Employing suitable prelithiation strategies could be a viable means to solve this problem. 
(a)

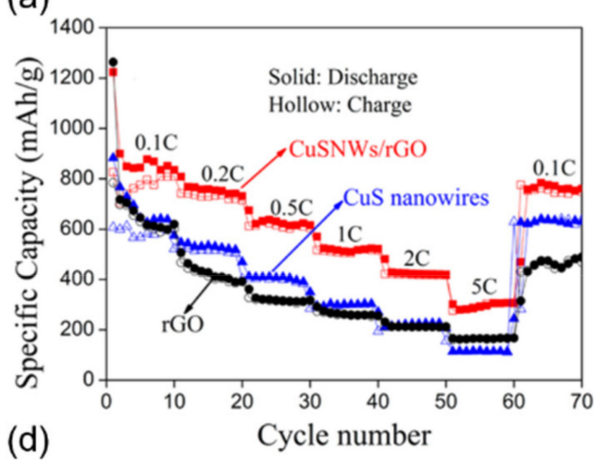

(d)

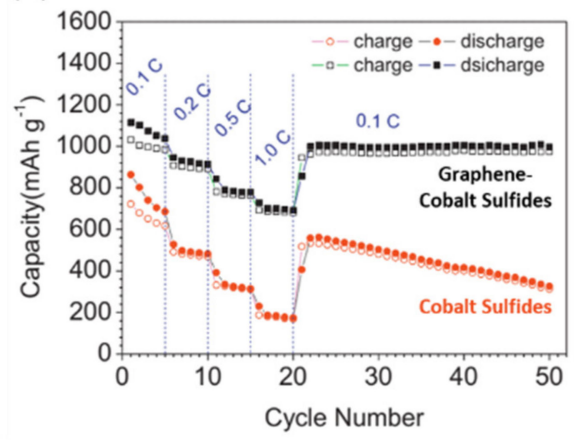

(b)

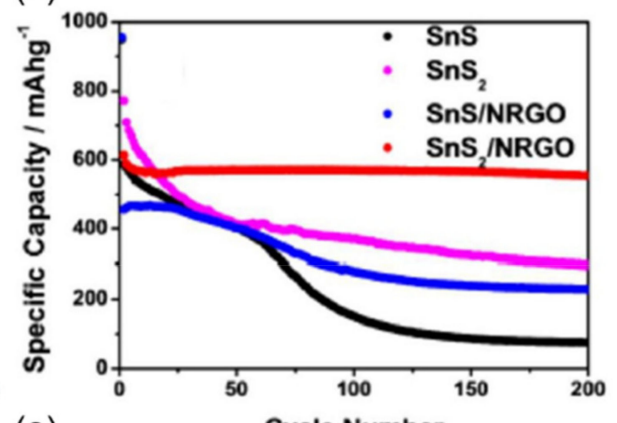

(e)

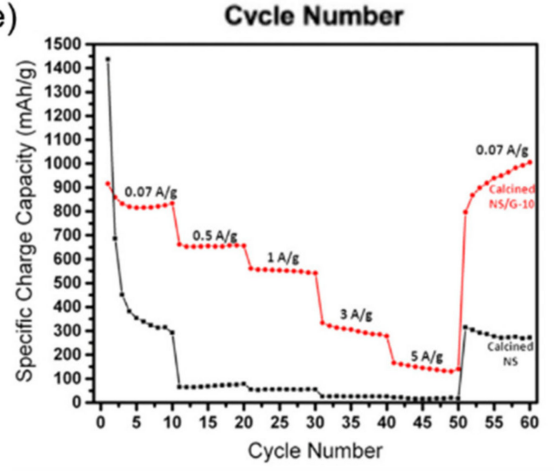

(c)

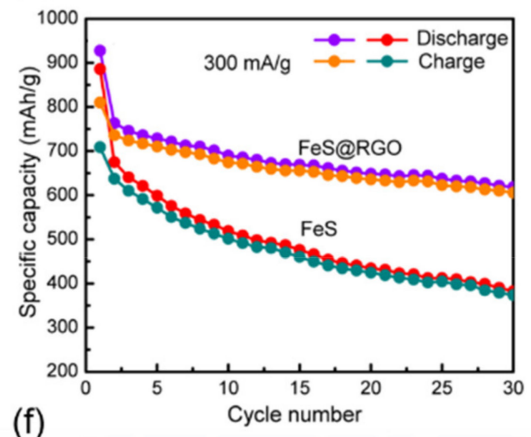

(f)

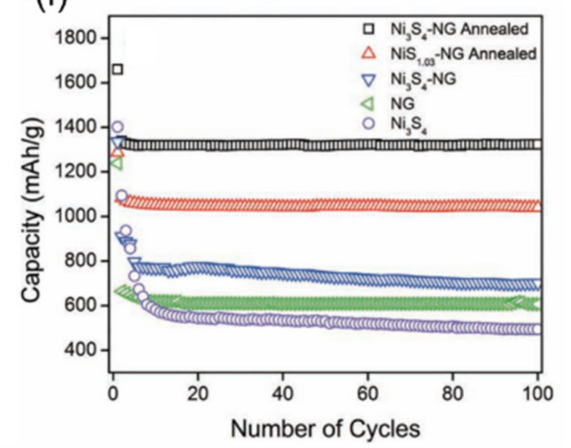

Figure 8. Cycle performance of graphene composite anode materials with (a) $\mathrm{CuS},(\mathbf{b}) \mathrm{SnS} / \mathrm{SnS}_{2}$, (c) FeS, (d) cobalt sulfides, (e) nickel sulfides, and (f) $\mathrm{Ni}_{3} \mathrm{~S}_{4} / \mathrm{NiS}_{1.03}$. Reproduced with permission from ref. [83-86,88,89], respectively. Copyright 2015, ACS Publications. Copyright 2016, ACS Publications. Copyright 2013, ACS Publications. Copyright 2013, Elsevier. Copyright 2016, Elsevier. Copyright 2013, Wiley.

\subsection{Graphene-Enhanced Lithium Metal and Lithiated Anode Materials}

Lithium metal anodes are among the most promising next-generation anode candidate for high-energy-density rechargeable batteries. Their extremely high specific capacity and the lowest standard reduction potential make them invincible in the race of boosting battery energy density [91,92]. Adopting lithium metal or lithiated anodes can also enable lithiumfree cathode materials (e.g., sulfur or air cathodes), which can deliver much higher capacity compared to conventional cathodes. However, after several decades of development, lithium metal anodes are still in lab-scale demonstration stages. Many challenges remain, such as uncontrolled lithium plating/stripping, dendritic and dead lithium formation, huge volume change between charge/discharge states, and repeated unstable SEI formation [91-95]. The surface of highly reactive lithium metal must be passivated, otherwise the continuous side reactions occurring at the interface between the lithium anode and electrolyte will keep deteriorating battery performance [94,95]. Many approaches using graphene to modify lithium metal and lithiated anodes have been reported with positive results [96-109].

First of all, highly conductive graphene with ultralarge surface area can play an important role as an excellent substrate to store lithium metal. Good electrical conductivity can promote fast charge transfer, and the continuous graphene network structure can uniformly distribute currents during electrochemical reactions, which can alleviate severe lithium dendrite formation. The issue of volume change between charge and discharge can be addressed by designing the void structure in the graphene-lithium metal composite architecture. Achieving a stable SEI is always the biggest challenge in non-graphite highcapacity anode systems (e.g., $\mathrm{Si}$ and $\mathrm{Li}$ ). Although graphene can serve as a graphite-like interface for coated active anode materials, the brittle characteristic of the SEI layer makes it unsustainable during the volume change of the anode structure. Therefore, a more rigid artificial SEI layer is necessary to pair with graphene for stable SEI growth on lithium metal anodes. 
Wang et al. synthesized a graphene cage embedded with gold particles as the container to store lithium metal [97]. Figure $9 a-d$ reveal lithium deposition and stripping using a graphene cage as the matrix. Since gold is a lithiophilic seeding material, lithium metal will prioritize its precipitation around the gold particles. The lithium metal will continue to deposit and fill in the internal space of the graphene cage. During the delithiation process, the lithium metal will be stripped away, and the graphene cage architecture is maintained. The graphene cage surface can offer a stable environment to form a thin SEM seal, and the internal void of the graphene cage can buffer the volume change during cycling. On the other hand, when the lithium metal plates onto the bare copper foil, a thick SEI layer forms with cracks. After extended cycles, a dendritic structure can be found in the lithium metal anode, and dead lithium will gradually be generated, leading to a serious capacity decay. The lithium plating and stripping behavior on the copper current collector are illustrated in Figure 9e-h. The graphene cage design has excellent structural stability, resulting in a good cycle life for over 300 cycles in lithium metal batteries when an appropriate high-concentration LiFSI electrolyte formulation was employed at the same time (Figure 9i). Even if using the graphene cage design alone without the LiFSI electrolyte, the graphene-enhanced lithium metal anode can still extend the cycle life to at least three times longer.

(a)

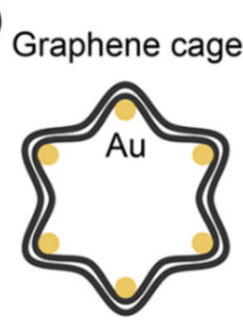

(e)

Copper foil

(i)

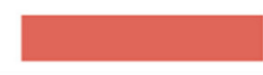

(b)

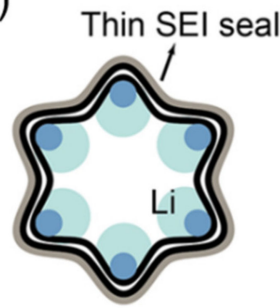

(f)

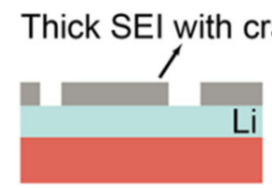

(c)

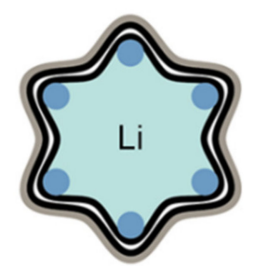

(g)

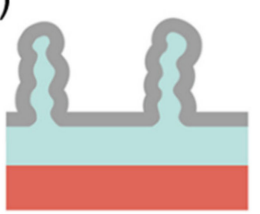

(d)

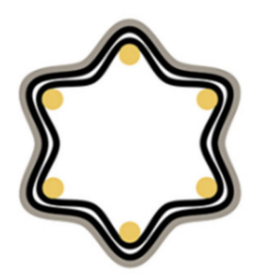

(h)

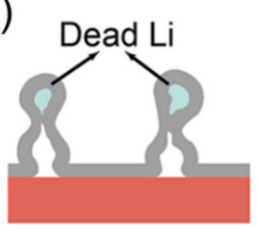

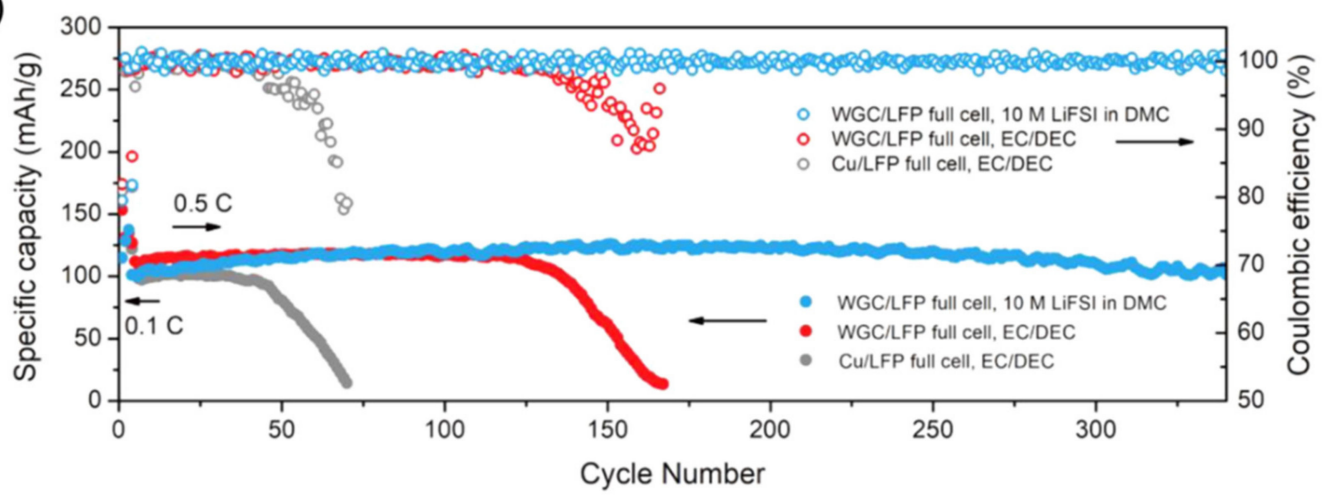

Figure 9. Comparison between the graphene cage and copper foil during Li deposition and stripping. (a) Pristine graphene cage. $(\mathbf{b}, \mathbf{c})$ The graphene cage after various amounts of Li deposition. (d) The graphene cage after Li stripping. (e) Bare copper foil. (f,g) The copper foil after various amounts of Li deposition. (h) The copper foil after Li stripping. (i) Full cell performance comparison between the graphene cage/Li electrodes and bare copper foil with electrodeposited Li metal under different electrolyte systems. Reproduced with permission from ref. [97]. Copyright 2019, ACS Publications.

Graphene can protect lithiated anode materials as well. Figure 10a exhibits a grapheneprotected lithiated silicon anode that is capable of rejecting gas penetration [98]. The gases in the air such as water, oxygen, and carbon dioxide will react with lithium metal and 
lithiated compounds to form $\mathrm{LiOH}, \mathrm{Li}_{2} \mathrm{O}$, and $\mathrm{Li}_{2} \mathrm{CO}_{3}$, which reduce the reversible anode capacity when they are assembled in cells. Figure $10 \mathrm{~b}$ compares the capacity of lithiated silicon $\left(\mathrm{Li}_{x} \mathrm{Si}\right)$ anode materials with and without the graphene protection when placed in a dry room for two weeks. The air in the dry room contains oxygen with reduced moisture. Unlike the bare $\mathrm{Li}_{x} \mathrm{Si}$ anode, the graphene-encapsulated $\mathrm{Li}_{x} \mathrm{Si}$ showed very stable capacity retention after two weeks of storage in the dry room, maintaining more than $90 \%$ of initial capacity. The results of a similar comparison in an ambient air environment can be seen in Figure 10c. Both anode samples exhibited faster capacity degradation due to the existence of moisture in the air. Nevertheless, the graphene-protected $\mathrm{Li}_{\mathrm{x}} \mathrm{Si}$ anode can still hold over $70 \%$ of initial capacity after resting for three days in ambient air, whereas the capacity of bare $\mathrm{Li}_{\mathrm{x}} \mathrm{Si}$ anode suddenly dropped to less than $20 \%$ just after six hours of storage.

(a)

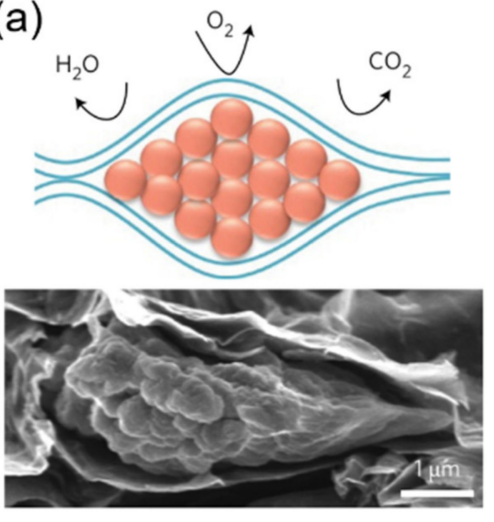

(b)

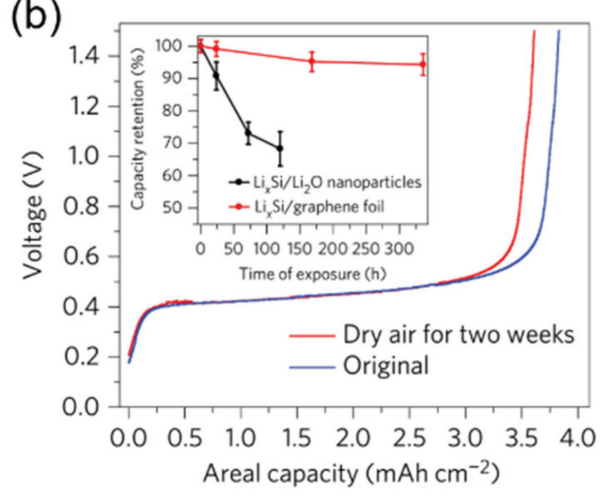

(c)

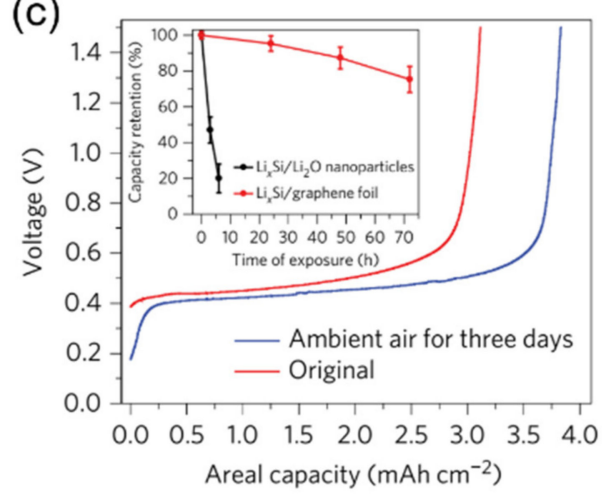

Figure 10. (a) Top: Schematic drawing of graphene sheets to avoid gas penetration. Bottom: Cross-sectional SEM image of $\mathrm{Li}_{\mathrm{x}} \mathrm{Si}$ nanoparticles encapsulated by the graphene sheets. (b) The capacity retention of the $\mathrm{Li}_{\mathrm{x}} \mathrm{Si} /$ graphene composite anode in the dry room for two weeks. (c) The capacity retention of the $\mathrm{Li}_{\mathrm{x}} \mathrm{Si}$ /graphene composite anode in ambient air for three days. Reproduced with permission from ref. [98]. Copyright 2017, Nature Publishing Group.

Here, graphene exhibits excellent sealing capability which blocks the gas penetration to protect lithiated compounds. This allows the operation of graphene-protected lithiated anodes in standard battery-grade dry rooms without adopting complicated processing methods that may require vacuum or inert gas systems. The outstanding sealing performance also makes graphene a good anti-leakage additive that can be used in the food-packaging and tire industries [110].

\section{Graphene-Enhanced Cathode Materials}

\subsection{Graphene-Enhanced Cathode Materials for Lithium-Ion Batteries}

Lithium cobalt oxide $\left(\mathrm{LiCoO}_{2}, \mathrm{LCO}\right)$ is the first commercialized cathode material for lithium-ion batteries. However, its comparatively high cost and the toxicity of cobalt are decreasing its market share, especially from the perspective of emerging electric vehicles and grid-level energy storage applications. Other cathode materials such as spinel lithium manganese oxide, olivine lithium transition-metal phosphates, and other layered metal oxides are gradually penetrating the market. The industry soon acknowledged that it was hard for a single cathode material to meet all requirements of different applications because of its intrinsic property limitations, for instance, density, voltage versus $\mathrm{Li} / \mathrm{Li}^{+}$, thermal stability, and electrical/ionic conductivity. Due to the uncertainty of how to choose an appropriate cathode material, corresponding studies to improve the variety of cathode materials have become one of the most active research areas. One topic that attracts much attention is solving the issue that all aforementioned non-LCO cathode materials have in common: low electrical conductivity. As a result, more conductive additives need to be added to electrodes in order to deliver the full capacity of these active materials, especially for high C-rate applications. The most common conductive additives to enhance the 
electrical conductivity at the electrode level are carbon blacks. Novel conductive additives such as carbon nanotubes (CNTs) and graphene have also been increasingly adopted in the battery industry. These conductive additives are considered as inactive components (i.e., do not contribute to the capacity) in the cathode. Furthermore, some studies pointed out that these conductive additives can cause irreversible lithium-ion loss at a higher voltage. Thus, their content in the cathode would be "the less the better". From this point of view, graphene as an emerging conductive additive has come under the spotlight. Graphene has the highest electrical conductivity (thanks to the $\mathrm{sp}^{2}$-bonded carbon atoms arranged in a hexagonal 2D lattice) and surface-to-mass ratio [111]. In comparison with carbon blacks, which are spherical nanoparticles, graphene can form plane-to-plane contact, instead of point-to-point contact, with active materials. Under the same percentage of additive content, graphene can more readily enable additional continuous pathways to allow electrons to freely travel within the electrode. Zhang et al. studied the percolation thresholds of graphene added to the lithium titanate oxide (LTO) anode [112]. The results indicated that the LTO anode containing $5 \mathrm{wt} . \%$ of graphene greatly outperformed the LTO anode with $15 \mathrm{wt} . \%$ of carbon black, owing to graphene's substantially low percolation threshold and high electrical conductivity. Although this study focused on the LTO anode, similar results can also be found in other cathode-related literature. For instance, Jiang et al. used $5 \mathrm{wt} . \%$ of reduced graphene oxide $(\mathrm{rGO})$ and $5 \mathrm{wt} . \%$ of carbon black as the conductive additives, and mixed them with the $\mathrm{LiNi}_{1 / 3} \mathrm{Mn}_{1 / 3} \mathrm{Co}_{1 / 3} \mathrm{O}_{2}$ (NMC333) cathode material and PVDF binder into a slurry, which was then pasted onto the current collector and formed an electrode. Compared to the control sample, which used $10 \mathrm{wt} . \%$ of carbon black, the addition of rGO significantly reduced the charge transfer resistance due to the improved electrical conductivity. The rate capability tests also showed that $5 \mathrm{wt} . \%$ of rGO significantly enhanced the capacity, especially when the C-rate was greater than $6 \mathrm{C}\left(110 \mathrm{~mA} \mathrm{~h} \mathrm{~g}^{-1}\right.$ versus nearly no capacity from the rGO-free electrode) [113]. Liu et al. also compared the rate performance of a lithium iron phosphate $\left(\mathrm{LiFePO}_{4}, \mathrm{LFP}\right)$ electrode with $1 \mathrm{wt} . \%$ of $\mathrm{rGO} / 10 \mathrm{wt} . \%$ of acetylene black and a control sample (with $11 \mathrm{wt} . \%$ acetylene black) at $1 \mathrm{C}$, $5 \mathrm{C}, 10 \mathrm{C}$, and $20 \mathrm{C}$. The former exhibited a reduced polarization and outperformed the latter in terms of reversible capacity at every tested C-rate [114]. The size and thickness of graphene when used as the conductive additive also influenced the general electrochemical performance of the cathode. This can be again explained by the percolation theory. The percolation threshold $\mathrm{V}_{\mathrm{G}}$ is given by:

$$
\mathrm{V}_{\mathrm{G}}=\left(27 \pi \mathrm{D}^{2} \mathrm{t}\right) /\left[4\left(\mathrm{D}+\mathrm{D}_{\mathrm{IP}}\right)^{3}\right]
$$

where $\mathrm{D}$ and $\mathrm{t}$ are the diameter and thickness of graphene nanosheets; $\mathrm{D}_{\mathrm{IP}}$ is the interparticle distance when electron hopping happens; and $D_{I P}=10 \mathrm{~nm}$ is generally assumed according to the quantum mechanical tunneling mechanism [112]. Since D $>>D_{I P}$ is usually the case, Zhang et al. further reduced Equation (1) to:

$$
\mathrm{V}_{\mathrm{G}} \approx(21.2 \mathrm{t}) / \mathrm{D}
$$

This denotes that the percolation threshold is inversely proportional to the graphene nanosheet's aspect ratio, meaning that the larger size and fewer layers of graphene should be more beneficial for lowering the content of graphene required to construct a continuous conductive network throughout the electrode.

Nevertheless, it was observed that the experimental results often deviated from the predicted values using Equation (2), and it seemed that a larger size of graphene was not always better. Hsu et al. reported the rate performance comparison of the NMC electrodes utilizing graphene in different lateral sizes (13 and $28 \mu \mathrm{m}$, denoted as GN-13 and GN-28; the thickness of both graphene nanosheets is similar) as the conductive agents [115]. The specific capacities of 189.2 and $114.2 \mathrm{~mA} \mathrm{~h} \mathrm{~g}^{-1}$ at $0.1 \mathrm{C}$ and $2 \mathrm{C}$, respectively, were achieved with GN-13, which are higher than those with GN-28 (179.4 and $6 \mathrm{~mA} \mathrm{~h} \mathrm{~g}^{-1}$ at $0.1 \mathrm{C}$ and $2 \mathrm{C}$, respectively). The latter even underperformed with the electrode solely with 
Super P conductive carbon black when the C-rate was $1 \mathrm{C}$ or higher. The authors found that the $\mathrm{Li}^{+}$diffusion coefficient of GN-13 was higher than that of $\mathrm{GN}-28$ and suggested that the longer $\mathrm{Li}^{+}$diffusion pathway was responsible for the lower capacity of GN-28. Tian et al. also measured the percolation thresholds of $\mathrm{LiNi}_{0.8} \mathrm{Mn}_{0.1} \mathrm{Co}_{0.1} \mathrm{O}_{2}(\mathrm{NMC} 811)$ electrodes with graphene or carbon black as conductive fillers, and the former displayed a higher value than the latter [116]. Their results actually indicated that the electrodes with the graphene additive exhibited lower specific capacity than that with the carbon black even when they were of the same mass fraction. The authors attributed it to a classic issue when using graphene as a conductive additive: graphene nanosheets tend to aggregate. Another team who studied the percolation thresholds of electrodes with graphene or carbon black reported an opposite result and highlighted the importance of an electrode preparation procedure to prevent graphene from aggregating in order to make the best of graphene as a conductive additive [117]. It is notable that the graphene powder used by Tian et al. consisted of many "defect-free" flakes. While the defect-free graphene means the structural integrity of graphene which ensures excellent electron transport, it also means that Li-ions are not allowed to diffuse through its basal plane $\left(\sim 10^{-11} \mathrm{~cm}^{2} \mathrm{~s}^{-1}\right)$, which can result in insufficient $\mathrm{Li}^{+}$migration channels, thereby deteriorating overall cell performance, especially rate capability [118]. Several methods, such as electron beam or argon ion irradiation $[119,120]$ and the nanoparticle-assisted etching process [121], to introduce vacancies (one type of defect) by removing carbon atoms from graphene might be potential solutions, and the related works have been well summarized by Sun et al. [118].

Graphene can not only be used as a conductive additive by simply being mixed into the slurry and then forming an electrode with cathode materials and binders, but can also participate the synthesis of cathode materials to shape their morphology or modify surface properties such as graphene-enhanced anode materials introduced in Section 3. These types of studies became rather popular when LFP started to attract much attention from the industry due to its advantages, such as low cost, better thermal stability, and environmental benignity. LFP has to be synthesized in an inert or reduced atmosphere, which is an ideal environment to incorporate graphene or GO, if used as the precursor of graphene, to form composites and take advantage of graphene's high electrical conductivity. A variety of synthesis methods, such as co-precipitation [122], hydrothermal [123], in situ solvothermal [124], spray drying [125], electrospinning [126], and microwave-assisted [127] synthetic routes, were reported to produce graphene- or rGO-enhanced LFP composites. The main benefits of synthesizing LFP in the presence of graphene or GO have been concluded as (1) improved high-rate performance due to the intimate contact between graphene and active materials (they can be chemically bonded in some cases), (2) less effort required to form homogeneous mixtures of graphene and LFP nanoparticles (no aggregation effect that negatively impacts the electrochemical performance), and (3) possibly less iron dissolution from LFP in electrolytes in the case of active particles being encapsulated by graphene or rGO. The electrochemical performance of the graphene-enhanced (or rGO-enhanced) LFP composites has been summarized multiple times and can be reviewed in [111,118,128-130].

Forming graphene/layered metal oxide cathode composites is more challenging. $\mathrm{LiNi}_{\mathrm{x}} \mathrm{Mn}_{\mathrm{y}} \mathrm{Co}_{1-\mathrm{x}-\mathrm{y}} \mathrm{O}_{2}$ series have become attractive because of their high gravimetric capacity, lower cost compared to LCO, and lower toxicity of $\mathrm{Ni}$ and $\mathrm{Mn}$ [131]. $\mathrm{LiNi}_{1 / 3} \mathrm{Mn}_{1 / 3} \mathrm{Co}_{1 / 3} \mathrm{O}_{2}$ (NMC333) and $\mathrm{LiNi}_{0.5} \mathrm{Mn}_{0.3} \mathrm{Co}_{0.2} \mathrm{O}_{2}$ (NMC532) have long been widely used in industry, but in recent years, the research interests have shifted to those with higher Ni content (Ni-rich) such as $\mathrm{LiNi}_{0.6} \mathrm{Mn}_{0.2} \mathrm{Co}_{0.2} \mathrm{O}_{2}$ (NMC622) and $\mathrm{LiNi}_{0.8} \mathrm{Mn}_{0.1} \mathrm{Co}_{0.1} \mathrm{O}_{2}$ (NMC811) owing to their substantial capacity enhancement [132]. The most common method to synthesize NMC cathode materials is co-precipitation, followed by a heat treatment (usually $>700{ }^{\circ} \mathrm{C}$ ). It has been reported that, during synthesis, the choice of atmoshere for the heat treatment can greatly influence the surface structural stability and electrochemical performance. For example, Shim et al. synthesized $\mathrm{LiNi}_{0.80} \mathrm{Co}_{0.15} \mathrm{Mn}_{0.05} \mathrm{O}_{2}$, which is very similar to NMC811, under two atmosphere conditions (oxygen and air) [133]. NiO rock-salt, which has poor 
$\mathrm{Li}^{+}$ion conductivity, was found only in the sample prepared in air, particularly on the surface of the particles. The authors supposed that the existence of $\mathrm{NiO}$ would be the cause of its inferior performance. After years of efforts, it has been acknowledged that while the NMC with Ni content $<0.5$ can be synthesized in air or an inert gas environment, NMC622 would need to be synthesized in air, and NMC811 or those with Ni content $>0.8$ have to be calcined in oxygen in order to prevent the formation of $\mathrm{NiO}$. Since graphene or GO will be burnt off at such a high temperature in air or oxygen, it is impossible to incorporate them in the synthesis process of NMC622 or NMC811, not like what can be achieved for graphene/LFP composites. Ni-rich NMCs as well as $\mathrm{LiNi}_{1-\mathrm{x}-\mathrm{y}} \mathrm{Co}_{\mathrm{x}} \mathrm{Al}_{\mathrm{y}} \mathrm{O}_{2}$ (NCA) are also sensitive to $\mathrm{H}_{2} \mathrm{O}$ [132], and therefore the spray drying process using GO aqueous solution is not an ideal approach either. Nevertheless, a few attempts have been made to produce graphene-NMC composites with improved performance. Jan et al. successfully prepared the graphene-NMC 811 composite by firstly grinding graphene and the as-prepared NMC811 powder, followed by dispersing the mixtures in ethanol by ultrasonication and drying [134]. Compared to pristine NMC811, the graphene composite exhibited higher capacity at $5 \mathrm{C}$ (127 vs. $160 \mathrm{~mA} \mathrm{~h} \mathrm{~g}^{-1}$, respectively) and a better cycle life. Park et al. produced a conformal graphene coating on NCA and NMC811 particles by employing an amphiphilic surfactant, 1,2-distearoylsn-glycero-3-phosphoethanolamine- $N$ [methoxy(polyethyleneglycol) (DSPE-mPEG), which acts as a glue to bind the hydrophobic basal plane of graphene to the hydrophilic lithium hydroxide or lithium carbonate on the surface of NCA or NMC811 particles, as shown in Figure 11 [135]. Their results showed that the conformal graphene coating could eliminate the necessity of adding carbon blacks as conductive additives and thus a high active material content ( $99 \mathrm{wt} . \%)$ and, as a result, a high electrode density $\left(\sim 4.3 \mathrm{~g} \mathrm{~cm}^{-3}\right.$ vs. $\sim 3.3 \mathrm{~g} \mathrm{~cm}^{-3}$ for $96 \mathrm{wt} . \%$ NCA electrode with the carbon black) were achieved. The areal capacity and volumetric capacity of the grapheneenhanced NCA can be greatly improved by $\sim 38 \%$ and $\sim 34 \%$, respectively, when matching against the electrode with the carbon black.

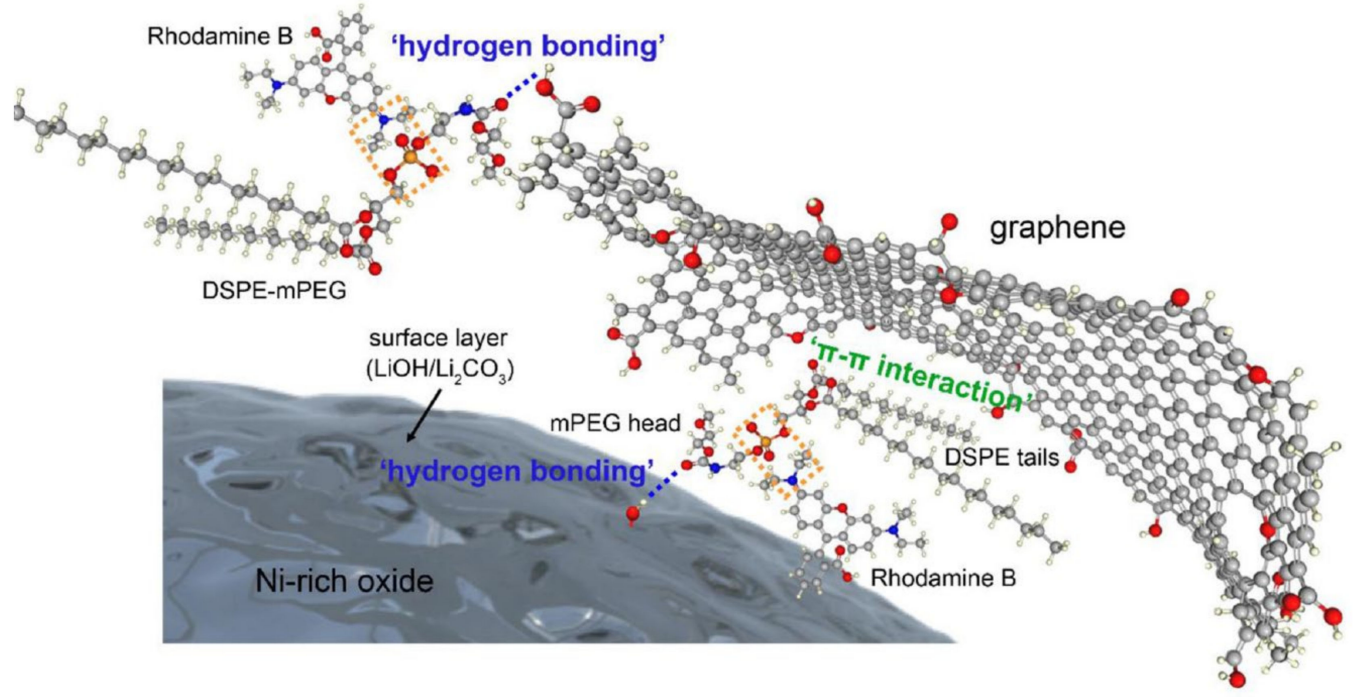

Figure 11. Schematic drawing of the bonding configuration between graphene and Ni-rich lithium metal oxide, where red, gray, ivory, blue, and orange colors represent oxygen, carbon, hydrogen, nitrogen, and phosphorus, correspondingly. Reproduced with permission from ref. [135]. Copyright 2021, Nature Publishing Group.

Similar to the aforementioned size issue of graphene as a conductive additive, the size of the graphene coating on NMC or NCA composites also seems to be an important factor that affects the electrochemical performance. He et al. prepared graphene nanodots $(\sim 5 \mathrm{~nm}$ in diameter) and $\mathrm{rGO}(\sim 2 \mu \mathrm{m})$-coated NCA [136]. The rate capability testing results of the two samples demonstrated opposite effects when compared to the pristine NCA: 
the sample coated with graphene nanodots showed improvement in capacity at all tested C-rates, while the rGO-coated sample displayed a lower capacity than that of the pristine sample at all tested C-rates. We summarize the results from two studies $[135,136]$ that both used $0.5 \mathrm{wt} . \%$ graphene (or $\mathrm{rGO}$ ) coating on NCA particles and present a visual comparison in Figure 12. The Y-axis represents the percentage of capacity changes defined as [(specific capacity of the coated sample) - (specific capacity of the non-coated sample)] divided by (specific capacity of the non-coated sample) at $0.1 \mathrm{C}$. The SEM micrographs clearly showed a more compact coating when the larger graphene (rGO) was used as the coating material. Since, again, $\mathrm{Li}^{+}$ions can only diffuse either through defects or along the edges of graphene nanosheets [137-139], a homogeneous coating with smaller graphene would possibly provide more $\mathrm{Li}^{+}$ion diffusion channels, thereby leading to positive effects in the layered lithium metal oxides in terms of electrochemical performance, as suggested by He et al. [136].

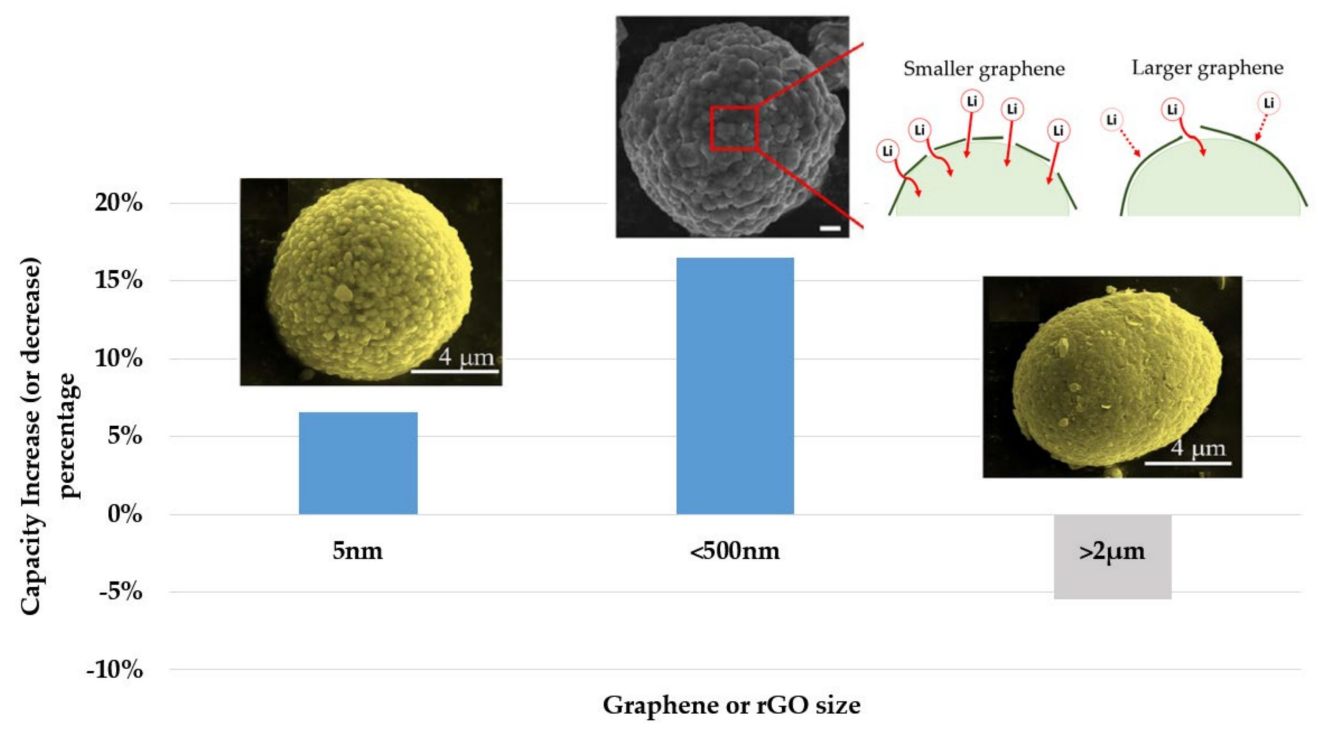

Figure 12. Comparison of specific capacity changes with the graphene (or rGO) coating with different flake sizes on NCA particles. The graphene (or rGO) contents of all samples are $0.5 \mathrm{wt} \%$. SEM micrographs on the left and right are from ref. [136] and the one in the center is from ref. [135], where the scale bar indicates $1 \mu \mathrm{m}$. Schematic drawing illustrates the concept of $\mathrm{Li}^{+}$ion diffusion pathways related to the flake sizes of graphene coating. Reproduced with permission from ref. [135,136]. Copyright 2021, Nature Publishing Group. Copyright 2019, the Electrochemical Society.

Studies that compared the capacities of pristine layered lithium metal oxides and their graphene or rGO composites in various structures, such as as cathode materials for Li-ion batteries, are summarized in Table 1.

To sum up, graphene has been proved as a promising material to improve the performance of cathode materials for Li-ion batteries. However, several factors such as lateral size, thickness, and defect concentration of graphene should be carefully determined in order to achieve the optimal performance of graphene-enhanced cathode materials. The balance between the numbers of $\mathrm{Li}^{+}$ion diffusion and continuous electron pathways is of paramount importance when one is considering how to best use graphene within the cathode. In addition to directly mixing graphene with cathode materials and binders to fabricate electrodes, many creative methods have been reported to be effective in producing composites with various structures. However, one will also need to scrutinize the cost and production scalability of these methods when it comes to commercialization. 
Table 1. The capacities of pristine layered lithium metal oxides and their graphene/rGO composites as cathode materials for Li-ion batteries.

\begin{tabular}{|c|c|c|c|c|c|}
\hline Name & Graphene Content & Structure Type & $\begin{array}{c}\text { Capacity }^{1} \\
\text { (Control Sample) }\end{array}$ & $\begin{array}{c}\text { Capacity }^{1} \\
\text { (Composite) }\end{array}$ & Ref. \\
\hline NMC811/rGO & 5.5 wt. $\%$ & Mixed & 158 & 185 & [134] \\
\hline NMC811/Graphene & 0.5 wt. $\%$ & Encapsulated & 175 & 190 & [135] \\
\hline NMC333/rGO & 10 wt. $\%$ & Mixed & 158 & 175 & [131] \\
\hline NMC333/rGO & 9 wt. \% (before reduction) & Encapsulated & 112 & 163 & [140] \\
\hline NMC333/Graphene & 2.3 wt. $\%$ & Encapsulated & 123 & 135 & [141] \\
\hline $\mathrm{NCA} / \mathrm{rGO}$ & 0.5 wt. $\%$ & Mixed & 168 & 180 & [142] \\
\hline NCA/Graphene & 0.5 wt. $\%$ & Encapsulated & 119 & 188 & [135] \\
\hline $\begin{array}{c}\text { NCA/Graphene } \\
\text { nanodot }\end{array}$ & 0.5 wt. $\%$ & Encapsulated & 150 & 175 & [136] \\
\hline LLNMC/rGO & 1.5 wt. $\%$ & Encapsulated & 150 & 230 & [143] \\
\hline LLNMC/Graphene & 0.5 wt. $\%$ & Anchored & 140 & 215 & [144] \\
\hline LLNMC/rGO & 4.9 wt. $\%$ & Encapsulated & 75 & 160 & [145] \\
\hline
\end{tabular}

${ }^{1}$ Specific capacity $\left(\mathrm{mA} \mathrm{h} \mathrm{g}^{-1}\right)$ at room temperature and $1 \mathrm{C}$. Control sample means the sample without graphene or rGO. Some numbers were extracted from the figures in the references by our best efforts.

\subsection{Graphene-Enhanced Sulfur Cathode Materials}

Sulfur is an emerging cathode material that has a high specific capacity $\left(1675 \mathrm{~mA} \mathrm{~h} \mathrm{~g}^{-1}\right)$ and is very cheap due to its abundance on Earth [146,147]. The roadblocks that hinder the practical applications of sulfur cathodes include that (1) sulfur is highly insulating, (2) the sulfur intermediates during electrochemical reactions, polysulfides, are easily dissolved in the electrolyte, and (3) the volume expands when sulfur transforms into lithium sulfide, resulting in an unstable electrode structure. To solve these problems, the mainstream approach is utilizing porous carbon host materials to accommodate sulfur, which can not only provide sufficient electron/ion channels but also lock polysulfide species in the matrix by the capillary action and absorption capability of the pore structure [146,147].

The structure of graphene is tunable via various processing methods, and it can be made porous for impregnation with sulfur as cathode materials. Many publications reported improved battery performance using graphene as the framework or coating material for sulfur cathodes [16,148-158]. Papandrea et al. used rGO sheets to build a 3D graphene framework to encapsulate sulfur as the cathode (Figure 13a,b) [148]. Graphene here functions as the conductive network and the active sulfur container, bifunctionally stabilizing the electrochemical reactions of lithium sulfur batteries. The authors also observed the motion of melted sulfur migrating within the graphene framework by employing in situ SEM techniques (Figure 13c-f). Melted sulfur was found gradually migrating out from its matrix but was obviously confined by the graphene wall structure without flowing out of the framework. This is a clear evidence that graphene possesses excellent sealing performance not only for gases (described in the previous section of the graphene-enhanced lithiated anode [98]) but also for liquid-phase materials. Other potential non-battery applications could utilize this unique behavior of graphene to trap substances that melt, vaporize, or sublime during reactions. 


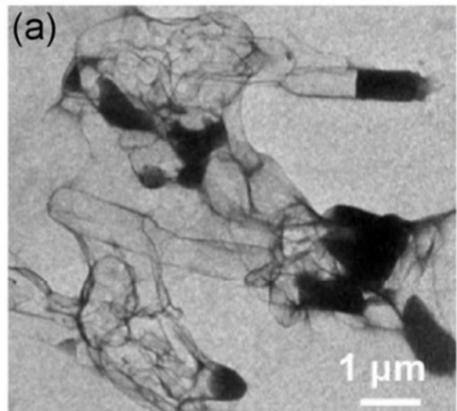

(b)
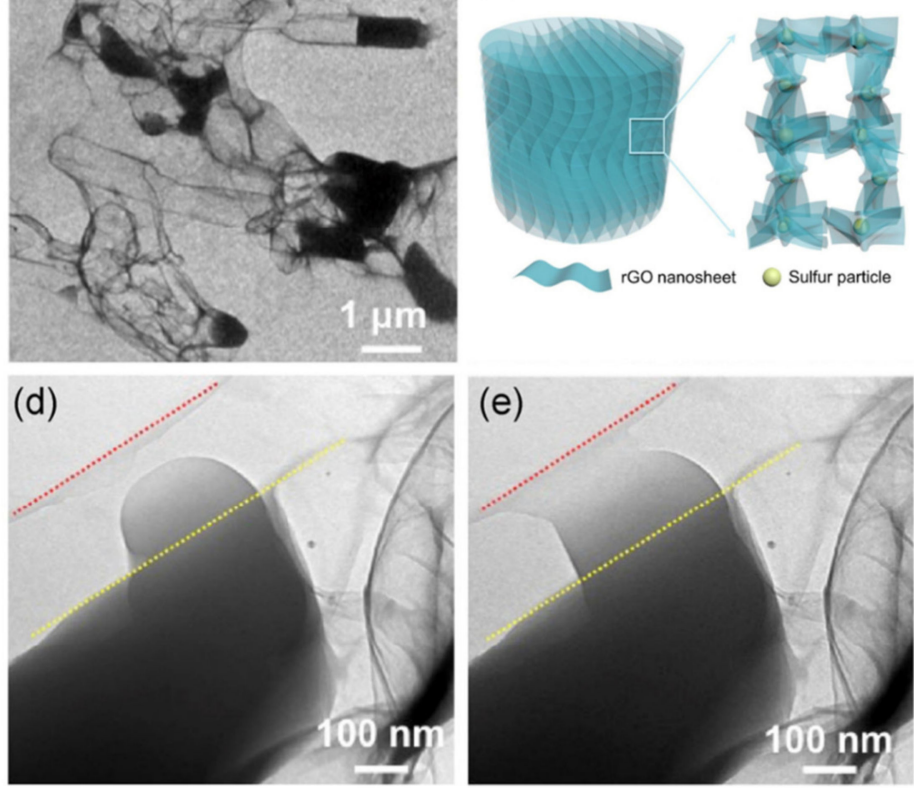

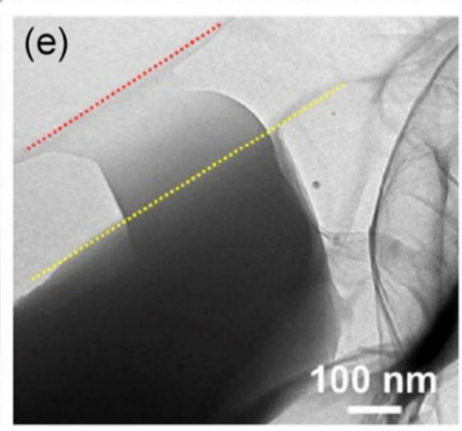

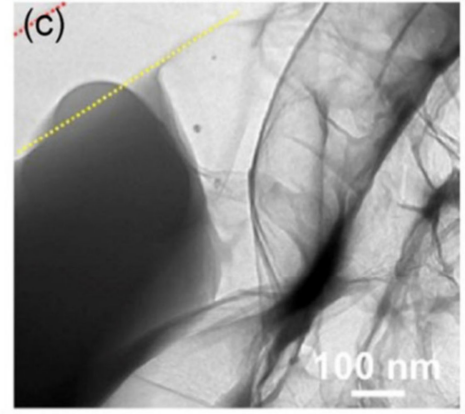

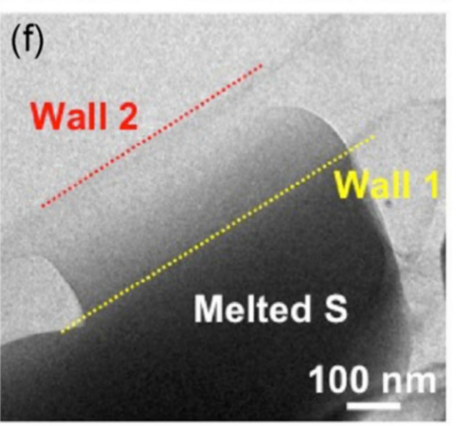

Figure 13. (a) TEM image of sulfur particles encapsulated in the 3D graphene structure. (b) Schematic drawing of freestanding 3D graphene-sulfur composite. (c-f) Multiple frames of melted sulfur migrating and being contained within the 3D graphene structure. Reproduced with permission from ref. [148]. Copyright 2016, Springer.

\section{Graphene-Enhanced Separators}

Since graphene is a 2D material with self-assembly ability, it can easily coat any flat substrate to make double-layer or multi-layer structures. Instead of coating on electrodes, fabricating a laminated structure on separators is an alternative option. Ceramic-coated separators are well-commercialized battery components in lithium-ion batteries with optimal safety features $[159,160]$. After applying ceramic coatings, the thermal stability and mechanical strength of separators are significantly enhanced. There are also numerous academic research studies showing that using a graphene coating instead of a ceramic coating can improve the performance of lithium metal and lithium sulfur batteries [161-171]. Since the polyolefin-based separators cannot withstand high temperatures, the processing of graphene coating will need additional attention to avoid thermal treatments, otherwise the separators may melt or become deformed.

Shin et al. employed a nitrogen and sulfur co-doped graphene-coated (NSG) separator toward the lithium metal anode side to suppress the lithium dendrite formation during cycling [165]. The dendritic lithium is a permanent safety issue because sharp lithium tips could puncture the separator, leading to cell internal short circuit. The application of graphene on the separator can assist in uniformly distributing current, stabilizing the reaction interface, and minimizing the impact of the pore structure on the separator (Figure 14a). The pore contact area will give less pressure and more electrolyte contact points over the lithium metal surface than the other area covered with polyolefin materials, causing heterogeneous lithium deposition. With the graphene coating on the separator, the pressure and electrolyte distribution become homogeneous, making the interfacial reactions on the lithium metal more stable. Among the cells, the one with the NSG separator provided the lowest interfacial resistances after 200 cycles (Figure 14b) due to the formation of a more stable SEI layer which can support more efficient ion transport during extended cycling [165]. 
(a)

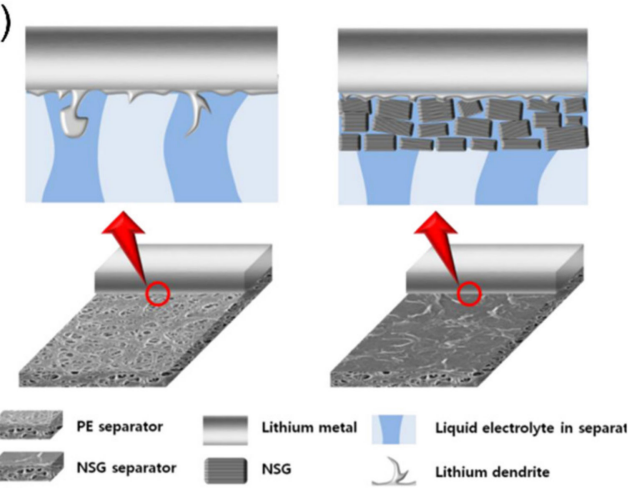

(c) PP Separator

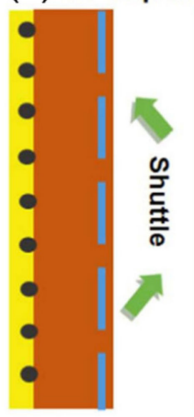

PG Separator

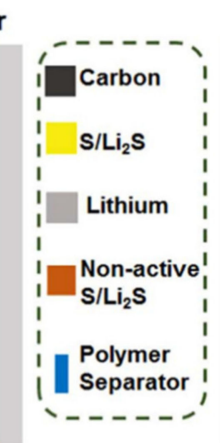

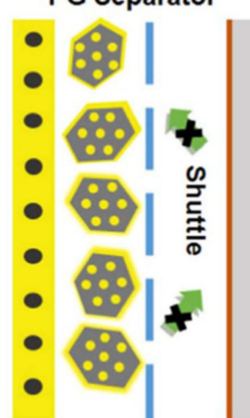

(b)
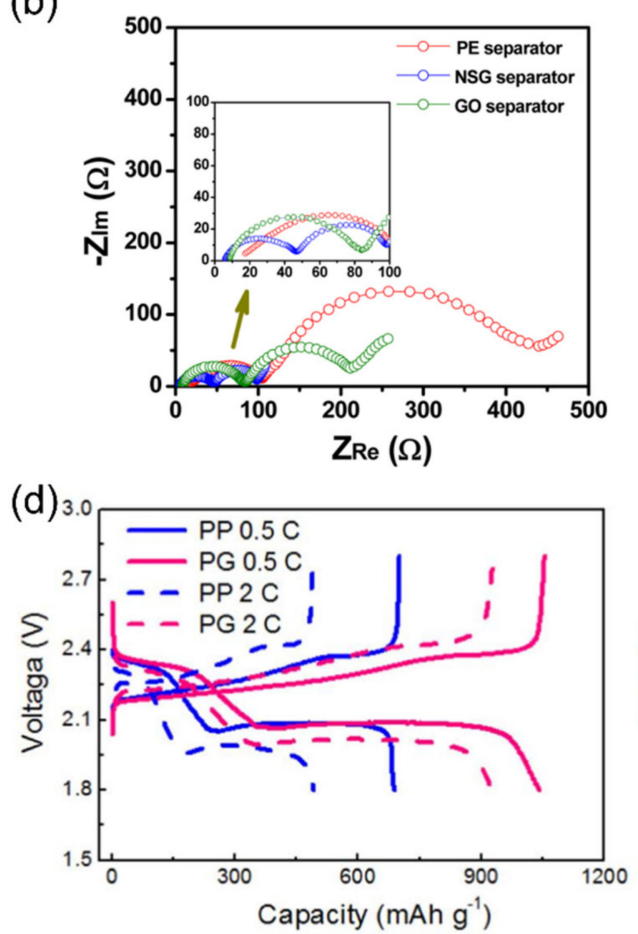

Figure 14. (a) Schematic drawing of dendrite growth on the lithium metal electrodes with the PE separator (left) and nitrogen and sulfur co-doped graphene-coated PE separator (right). (b) AC impedance spectra of the Li metal cells assembled with different separators after 200 cycles. Reproduced with permission from ref. [165]. Copyright 2015, ACS Publications. (c) Schematic drawing of reaction difference between the PP and porous graphene (PG) separators at the sulfur cathode/separator interface. (d) Galvanostatic charge-discharge profiles at $0.5 \mathrm{C}$ and $2 \mathrm{C}$. Reproduced with permission from ref. [167]. Copyright 2016, Elsevier.

The shuttle effect is notorious in lithium sulfur battery systems, resulting from the soluble polysulfides moving back and forth between the lithium metal anode and sulfur cathode $[146,147]$. The incessant migration of polysulfide ions will induce a non-stop charging behavior in the cell. An effective method called "interlayer configuration" was developed to tackle this issue by placing a porous carbonaceous material in between the sulfur cathode and separator [172,173]. This interlayer can be further integrated into the separator architecture to streamline lithium sulfur cell manufacturing [174-176]. Zhai et al. used a porous graphene-coated (PG) polymer separator in lithium sulfur batteries, but toward the sulfur cathode side shown, as shown in Figure 14c [167]. The significant enhancement of electron/lithium-ion transfer offered by the PG separator was confirmed by remarkably reduced overpotential shown in the galvanostatic chargedischarge curves, especially at a higher C-rate (Figure 14d) [167]. Thanks to the tunable structure of graphene material design, the graphene with a porous structure sticking on the separator can efficiently absorb the polysulfides migrating from the sulfur cathode and reutilize the trapped sulfur species in the following cycles, which evidently prolong the cycle life and reduce the capacity degradation of lithium sulfur cells.

\section{Graphene-Enhanced Current Collectors}

Current collectors have been found to be an essential component that can influence the performance of lithium-ion batteries. Aluminum and copper foils are selected as the current collectors for the cathode and anode, respectively, because of their relatively low cost and high electrical conductivity. General issues of these two commonly used current collectors are (1) the corrosion of $\mathrm{Al}$ current collectors, which can lead to internal resistance increase, serious self-discharge, and possible micro-short circuit induced by $\mathrm{Al}$ fragments under 
extensive cycles [177,178], at a relatively high potential, (2) poor adhesion between current collectors and electrode materials, and (3) comparatively high mass ratio (9-10 wt.\%) in the battery [118].

The root cause of $\mathrm{Al}$ current collector corrosion was generally believed to be the decomposition of $\mathrm{LiPF}_{6}$ salt in electrolytes [179]. Recently, Ma et al. found that the corrosion of $\mathrm{Al}$ foils was triggered by the electrochemical oxidation of solvent molecules such as ethylene carbonate and a coupled electrochemical-chemical reaction [180]. A few studies have reported an anti-corrosion effect from the success of adopting a graphene coating on the surface of Al current collectors (Figure 15a) [177]. For example, Wang et al. directly grew a multilayer graphene film $(5 \sim 10 \mathrm{~nm})$ on the $\mathrm{Al}$ current collector via plasma-enhanced chemical vapor deposition (PECVD) [177]. They used $\mathrm{LiMn}_{2} \mathrm{O}_{4} / \mathrm{LiPF}_{6}$ as a model system to investigate the anti-corrosion effect of the graphene-coated current collector. Figure $15 b, c$ compare the $\mathrm{CV}$ curves of $\mathrm{Al}$ current collectors with and without the graphene passivation layer in $\mathrm{LiPF}_{6}$ electrolyte at the 1st, 3rd, and 5th cycle. With the pristine $\mathrm{Al}(\mathrm{PA})$ current collector, the upturn inflection voltage increases dramatically at the 5th cycle, implying the local breakdown of the protective passive layers [177]. In contrast, the upturn inflection voltage of graphene-armored $\mathrm{Al}$ (GA) foil is significantly elevated up to $\approx 4.5 \mathrm{~V}$ (vs. $\mathrm{Li}^{+} / \mathrm{Li}$ ), exhibiting excellent stability toward anodic corrosion [177]. The results clearly showed that with a graphene coating, no appreciable change appeared on the surface of Al current collector, while many "scars" were observed on the pristine sample (Figure 15d,e). Similar results were reported by several other groups, where a graphene or GO coating was applied via different methods such as electro-spraying [181], CVD growth followed by transfer using thermal release tapes [182], and spin-coating [183]. All three groups presented improved long-term electrochemical performance from the graphene-coated $\mathrm{Al}$ current collectors.

(a)

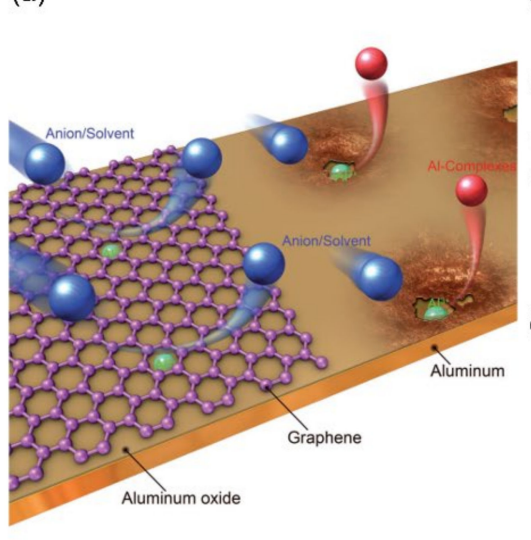

(b)

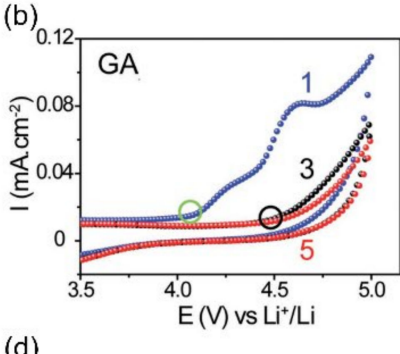

(c)

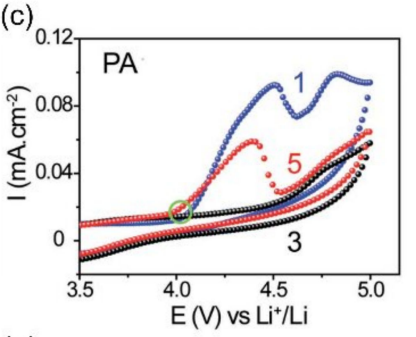

(e)
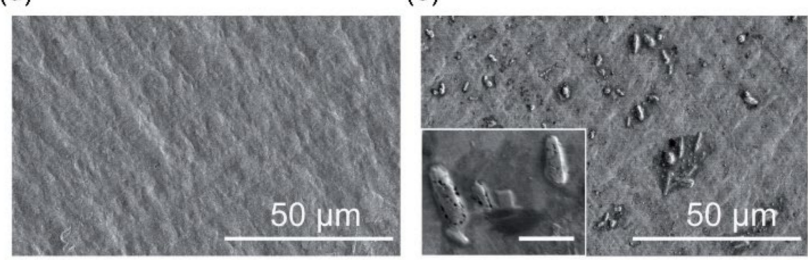

Figure 15. (a) Schematic illustration of graphene-armored aluminum foil with enhanced anti-corrosion property as current

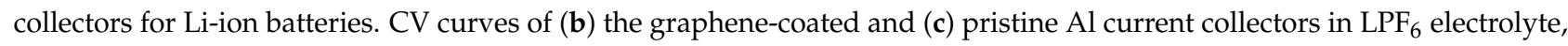
and the number denotes the cycle index. SEM micrographs of (d) the graphene-coated and (e) pristine Al current collectors after cyclic voltammetry scanning for 5 cycles in the $\mathrm{LiPF}_{6}$-based carbonate electrolyte. Reproduced with permission from ref. [177]. Copyright 2017, Wiley.

As a battery component that bridges electrode materials and external circuits, good interfacial contact, meaning stronger adhesion and lower contact resistance, is essential to the battery performance, especially for high C-rate applications. Kim et al. demonstrated that with a graphene coating layer, the adhesion strength can be significantly enhanced if it is of an appropriate thickness [182]. Lastly, despite the key role of current collectors, they are still inactive materials that have a significant mass fraction in a battery. Some alternative types of current collectors such as free-standing graphene-based papers and 
graphene-coated plastic films have been proposed [184,185]. More related studies have been previously summarized in ref. [118].

\section{Summary and Outlook}

Graphene is a wonder material with ultrahigh electrical/thermal conductivity, good mechanical strength, large surface area, special sealing performance, and structural tunability. The synthesis of graphene composite materials can be modified considering the processing requirements and raw material limitations. The idea is to utilize the advantages of graphene without degrading raw materials during the production of composite materials.

Due to the tunable nature of graphene structures and processing methods, it can combine with anodes, cathodes, separators, and current collectors to make advanced battery components for lithium-ion and lithium metal batteries. The commercialization of graphene technologies is an ongoing process in industry. There are already plenty of graphene-enhanced battery-related products in the energy storage market. The high cost of single-layer graphene may inhibit the practicality of its large-scale production, but some applications may be capable of gaining improvements by employing few-layer graphene materials. As a result, the commercialization of graphene technologies largely depends on their cost-effectiveness.

The challenges of graphene applications remain, including producing graphene with good performance by adopting low-cost production techniques, the performance improvement that has to be directly proportional to the cost of graphene added, and the advancement of large-scale processing technologies.

Author Contributions: H.-H.C. was responsible for the review of graphene-enhanced cathode and current collector materials. T.-H.H. assisted in the literature survey and screening. Y.-S.S. was responsible for the review of graphene-enhanced anode and separator materials, and prepared the Abstract, Introduction, and Summary and Outlook. All authors participated in writing the manuscript and discussing the contents to be included in this review together. All authors have read and agreed to the published version of the manuscript.

Funding: This research was funded by the Ministry of Education (MOE) in Taiwan under the Yushan Young Scholar Program (110B53-8) and Higher Education SPROUT Project (110W281).

Institutional Review Board Statement: Not applicable.

Informed Consent Statement: Not applicable.

Data Availability Statement: All collected data are presented in the manuscript.

Conflicts of Interest: The authors declare no conflict of interest.

\section{References}

1. Novoselov, K.S. Electric Field Effect in Atomically Thin Carbon Films. Science 2004, 306, 666-669. [CrossRef] [PubMed]

2. Jang, B.Z.; Huang, W.C. Nano-Scaled Graphene Plates. U.S. Patent 7,071,258 B1, 4 July 2006.

3. The Nobel Prize in Physics 2010. Available online: https://www.nobelprize.org/prizes/physics/2010/summary/ (accessed on 28 July 2021).

4. The Nobel Prize in Chemistry 2019. Available online: https://www.nobelprize.org/prizes/chemistry/2019/summary/ (accessed on 25 August 2021).

5. Whittingham, M.S. Lithium Batteries and Cathode Materials. Chem. Rev. 2004, 104, 4271-4302. [CrossRef] [PubMed]

6. Marom, R.; Amalraj, S.F.; Leifer, N.; Jacob, D.; Aurbach, D. A Review of Advanced and Practical Lithium Battery Materials. J. Mater. Chem. 2011, 21, 9938. [CrossRef]

7. Li, M.; Lu, J.; Chen, Z.; Amine, K. 30 Years of Lithium-Ion Batteries. Adv. Mater. 2018, 30, 1800561. [CrossRef]

8. El-Kady, M.F.; Shao, Y.; Kaner, R.B. Graphene for Batteries, Supercapacitors and Beyond. Nat. Rev. Mater. 2016, 1, 16033. [CrossRef]

9. Kausar, A. Applications of Polymer/Graphene Nanocomposite Membranes: A Review. Mater. Res. Innov. 2019, 23, 276-287. [CrossRef]

10. Geim, A.K. Graphene: Status and Prospects. Science 2009, 324, 1530-1534. [CrossRef] 
11. Novoselov, K.S.; Fal'ko, V.I.; Colombo, L.; Gellert, P.R.; Schwab, M.G.; Kim, K. A Roadmap for Graphene. Nature 2012, 490, 192-200. [CrossRef]

12. Li, D.; Kaner, R.B. MATERIALS SCIENCE: Graphene-Based Materials. Science 2008, 320, 1170-1171. [CrossRef]

13. Choi, W.; Lahiri, I.; Seelaboyina, R.; Kang, Y.S. Synthesis of Graphene and Its Applications: A Review. Crit. Rev. Solid State Mater. Sci. 2010, 35, 52-71. [CrossRef]

14. Stoller, M.D.; Park, S.; Zhu, Y.; An, J.; Ruoff, R.S. Graphene-Based Ultracapacitors. Nano Lett. 2008, 8, 3498-3502. [CrossRef]

15. Raccichini, R.; Varzi, A.; Passerini, S.; Scrosati, B. The Role of Graphene for Electrochemical Energy Storage. Nat. Mater. 2015, 14, 271-279. [CrossRef]

16. Wu, S.; Ge, R.; Lu, M.; Xu, R.; Zhang, Z. Graphene-Based Nano-Materials for Lithium-Sulfur Battery and Sodium-Ion Battery. Nano Energy 2015, 15, 379-405. [CrossRef]

17. Mohan, V.B.; Lau, K.; Hui, D.; Bhattacharyya, D. Graphene-Based Materials and Their Composites: A Review on Production, Applications and Product Limitations. Compos. Part B Eng. 2018, 142, 200-220. [CrossRef]

18. Lee, X.J.; Hiew, B.Y.Z.; Lai, K.C.; Lee, L.Y.; Gan, S.; Thangalazhy-Gopakumar, S.; Rigby, S. Review on Graphene and Its Derivatives: Synthesis Methods and Potential Industrial Implementation. J. Taiwan Inst. Chem. Eng. 2019, 98, 163-180. [CrossRef]

19. Kumar, S.; Chatterjee, K. Comprehensive Review on the Use of Graphene-Based Substrates for Regenerative Medicine and Biomedical Devices. ACS Appl. Mater. Interfaces 2016, 8, 26431-26457. [CrossRef]

20. Dhand, V.; Rhee, K.Y.; Ju Kim, H.; Ho Jung, D. A Comprehensive Review of Graphene Nanocomposites: Research Status and Trends. J. Nanomater. 2013, 2013, 763953. [CrossRef]

21. Hidalgo-Manrique, P.; Lei, X.; Xu, R.; Zhou, M.; Kinloch, I.A.; Young, R.J. Copper/Graphene Composites: A Review. J. Mater. Sci. 2019, 54, 12236-12289. [CrossRef]

22. Li, Y.; Feng, Z.; Huang, L.; Essa, K.; Bilotti, E.; Zhang, H.; Peijs, T.; Hao, L. Additive Manufacturing High Performance Graphene-Based Composites: A Review. Compos. Part Appl. Sci. Manuf. 2019, 124, 105483. [CrossRef]

23. Cui, G.; Bi, Z.; Zhang, R.; Liu, J.; Yu, X.; Li, Z. A Comprehensive Review on Graphene-Based Anti-Corrosive Coatings. Chem. Eng. J. 2019, 373, 104-121. [CrossRef]

24. Ding, R.; Li, W.; Wang, X.; Gui, T.; Li, B.; Han, P.; Tian, H.; Liu, A.; Wang, X.; Liu, X.; et al. A Brief Review of Corrosion Protective Films and Coatings Based on Graphene and Graphene Oxide. J. Alloys Compd. 2018, 764, 1039-1055. [CrossRef]

25. Kong, W.; Kum, H.; Bae, S.-H.; Shim, J.; Kim, H.; Kong, L.; Meng, Y.; Wang, K.; Kim, C.; Kim, J. Path towards Graphene Commercialization from Lab to Market. Nat. Nanotechnol. 2019, 14, 927-938. [CrossRef]

26. Ren, W.; Cheng, H.-M. The Global Growth of Graphene. Nat. Nanotechnol. 2014, 9, 726-730. [CrossRef] [PubMed]

27. Li, G.; Mo, X.; Law, W.-C.; Chan, K.C. 3D Printed Graphene/Nickel Electrodes for High Areal Capacitance Electrochemical Storage. J. Mater. Chem. A 2019, 7, 4055-4062. [CrossRef]

28. Ghany, N.A.A.; Elsherif, S.A.; Handal, H.T. Revolution of Graphene for Different Applications: State-of-the-Art. Surf. Interfaces 2017, 9, 93-106. [CrossRef]

29. Sun, J.; Chen, Y.; Priydarshi, M.K.; Gao, T.; Song, X.; Zhang, Y.; Liu, Z. Graphene Glass from Direct CVD Routes: Production and Applications. Adv. Mater. 2016, 28, 10333-10339. [CrossRef] [PubMed]

30. Brownson, D.A.C.; Banks, C.E. The Electrochemistry of CVD Graphene: Progress and Prospects. Phys. Chem. Chem. Phys. 2012, 14, 8264. [CrossRef]

31. Porwal, H.; Grasso, S.; Reece, M.J. Review of Graphene-Ceramic Matrix Composites. Adv. Appl. Ceram. 2013, 112, 443-454. [CrossRef]

32. Ciesielski, A.; Samorì, P. Graphene via Sonication Assisted Liquid-Phase Exfoliation. Chem. Soc. Rev. 2014, 43, 381-398. [CrossRef] [PubMed]

33. Hummers, W.S.; Offeman, R.E. Preparation of Graphitic Oxide. J. Am. Chem. Soc. 1958, 80, 1339. [CrossRef]

34. Zaaba, N.I.; Foo, K.L.; Hashim, U.; Tan, S.J.; Liu, W.-W.; Voon, C.H. Synthesis of Graphene Oxide Using Modified Hummers Method: Solvent Influence. Procedia Eng. 2017, 184, 469-477. [CrossRef]

35. Krishnan, D.; Kim, F.; Luo, J.; Cruz-Silva, R.; Cote, L.J.; Jang, H.D.; Huang, J. Energetic Graphene Oxide: Challenges and Opportunities. Nano Today 2012, 7, 137-152. [CrossRef]

36. Bai, H.; Li, C.; Shi, G. Functional Composite Materials Based on Chemically Converted Graphene. Adv. Mater. 2011, 23, 1089-1115. [CrossRef] [PubMed]

37. Zhang, S.S. A Review on the Separators of Liquid Electrolyte Li-Ion Batteries. J. Power Sources 2007, 164, 351-364. [CrossRef]

38. Wu, Y.P.; Rahm, E.; Holze, R. Carbon Anode Materials for Lithium Ion Batteries. J. Power Sources 2003, 114, 228-236. [CrossRef]

39. An, S.J.; Li, J.; Daniel, C.; Mohanty, D.; Nagpure, S.; Wood, D.L. The State of Understanding of the Lithium-Ion-Battery Graphite Solid Electrolyte Interphase (SEI) and Its Relationship to Formation Cycling. Carbon 2016, 105, 52-76. [CrossRef]

40. Zhang, W.-J. A Review of the Electrochemical Performance of Alloy Anodes for Lithium-Ion Batteries. J. Power Sources 2011, 196, 13-24. [CrossRef]

41. Wang, F.; Chen, G.; Zhang, N.; Liu, X.; Ma, R. Engineering of Carbon and Other Protective Coating Layers for Stabilizing Silicon Anode Materials. Carbon Energy 2019, 1, 219-245. [CrossRef]

42. Liu, X.H.; Zhong, L.; Huang, S.; Mao, S.X.; Zhu, T.; Huang, J.Y. Size-Dependent Fracture of Silicon Nanoparticles During Lithiation. ACS Nano 2012, 6, 1522-1531. [CrossRef] 
43. Jin, Y.; Zhu, B.; Lu, Z.; Liu, N.; Zhu, J. Challenges and Recent Progress in the Development of Si Anodes for Lithium-Ion Battery. Adv. Energy Mater. 2017, 7, 1700715. [CrossRef]

44. Zhang, S. Chemomechanical Modeling of Lithiation-Induced Failure in High-Volume-Change Electrode Materials for Lithium Ion Batteries. Npj Comput. Mater. 2017, 3, 7. [CrossRef]

45. Wang, B.; Li, X.; Zhang, X.; Luo, B.; Jin, M.; Liang, M.; Dayeh, S.A.; Picraux, S.T.; Zhi, L. Adaptable Silicon-Carbon Nanocables Sandwiched between Reduced Graphene Oxide Sheets as Lithium Ion Battery Anodes. ACS Nano 2013, 7, 1437-1445. [CrossRef] [PubMed]

46. Ko, M.; Chae, S.; Jeong, S.; Oh, P.; Cho, J. Elastic $a$-Silicon Nanoparticle Backboned Graphene Hybrid as a Self-Compacting Anode for High-Rate Lithium Ion Batteries. ACS Nano 2014, 8, 8591-8599. [CrossRef] [PubMed]

47. Zhou, X.; Yin, Y.-X.; Wan, L.-J.; Guo, Y.-G. Facile Synthesis of Silicon Nanoparticles Inserted into Graphene Sheets as Improved Anode Materials for Lithium-Ion Batteries. Chem. Commun. 2012, 48, 2198. [CrossRef] [PubMed]

48. Wang, J.-Z.; Zhong, C.; Chou, S.-L.; Liu, H.-K. Flexible Free-Standing Graphene-Silicon Composite Film for Lithium-Ion Batteries. Electrochem. Commun. 2010, 12, 1467-1470. [CrossRef]

49. Xiang, H.; Zhang, K.; Ji, G.; Lee, J.Y.; Zou, C.; Chen, X.; Wu, J. Graphene/Nanosized Silicon Composites for Lithium Battery Anodes with Improved Cycling Stability. Carbon 2011, 49, 1787-1796. [CrossRef]

50. Li, Y.; Yan, K.; Lee, H.-W.; Lu, Z.; Liu, N.; Cui, Y. Growth of Conformal Graphene Cages on Micrometre-Sized Silicon Particles as Stable Battery Anodes. Nat. Energy 2016, 1, 15029. [CrossRef]

51. Zhou, M.; Li, X.; Wang, B.; Zhang, Y.; Ning, J.; Xiao, Z.; Zhang, X.; Chang, Y.; Zhi, L. High-Performance Silicon Battery Anodes Enabled by Engineering Graphene Assemblies. Nano Lett. 2015, 15, 6222-6228. [CrossRef]

52. Lee, J.K.; Smith, K.B.; Hayner, C.M.; Kung, H.H. Silicon Nanoparticles-Graphene Paper Composites for Li Ion Battery Anodes. Chem. Commun. 2010, 46, 2025. [CrossRef] [PubMed]

53. Son, I.H.; Hwan Park, J.; Kwon, S.; Park, S.; Rümmeli, M.H.; Bachmatiuk, A.; Song, H.J.; Ku, J.; Choi, J.W.; Choi, J.; et al. Silicon Carbide-Free Graphene Growth on Silicon for Lithium-Ion Battery with High Volumetric Energy Density. Nat. Commun. 2015, 6, 7393. [CrossRef]

54. Eom, K.; Joshi, T.; Bordes, A.; Do, I.; Fuller, T.F. The Design of a Li-Ion Full Cell Battery Using a Nano Silicon and Nano Multi-Layer Graphene Composite Anode. J. Power Sources 2014, 249, 118-124. [CrossRef]

55. Ji, J.; Ji, H.; Zhang, L.L.; Zhao, X.; Bai, X.; Fan, X.; Zhang, F.; Ruoff, R.S. Graphene-Encapsulated Si on Ultrathin-Graphite Foam as Anode for High Capacity Lithium-Ion Batteries. Adv. Mater. 2013, 25, 4673-4677. [CrossRef]

56. Luo, J.; Zhao, X.; Wu, J.; Jang, H.D.; Kung, H.H.; Huang, J. Crumpled Graphene-Encapsulated Si Nanoparticles for Lithium Ion Battery Anodes. J. Phys. Chem. Lett. 2012, 3, 1824-1829. [CrossRef] [PubMed]

57. Xu, Q.; Sun, J.; Yu, Z.; Yin, Y.; Xin, S.; Yu, S.; Guo, Y. SiO $x$ Encapsulated in Graphene Bubble Film: An Ultrastable Li-Ion Battery Anode. Adv. Mater. 2018, 30, 1707430. [CrossRef]

58. Shi, L.; Pang, C.; Chen, S.; Wang, M.; Wang, K.; Tan, Z.; Gao, P.; Ren, J.; Huang, Y.; Peng, H.; et al. Vertical Graphene Growth on $\mathrm{SiO}$ Microparticles for Stable Lithium Ion Battery Anodes. Nano Lett. 2017, 17, 3681-3687. [CrossRef]

59. Chen, K.-S.; Balla, I.; Luu, N.S.; Hersam, M.C. Emerging Opportunities for Two-Dimensional Materials in Lithium-Ion Batteries. ACS Energy Lett. 2017, 2, 2026-2034. [CrossRef]

60. Mo, R.; Rooney, D.; Sun, K.; Yang, H.Y. 3D Nitrogen-Doped Graphene Foam with Encapsulated Germanium/Nitrogen-Doped Graphene Yolk-Shell Nanoarchitecture for High-Performance Flexible Li-Ion Battery. Nat. Commun. 2017, 8, 13949. [CrossRef] [PubMed]

61. Cheng, J.; Du, J. Facile Synthesis of Germanium-Graphene Nanocomposites and Their Application as Anode Materials for Lithium Ion Batteries. CrystEngComm 2012, 14, 397-400. [CrossRef]

62. Ren, J.-G.; Wu, Q.-H.; Tang, H.; Hong, G.; Zhang, W.; Lee, S.-T. Germanium-Graphene Composite Anode for High-Energy Lithium Batteries with Long Cycle Life. J. Mater. Chem. A 2013, 1, 1821-1826. [CrossRef]

63. Yuan, F.-W.; Tuan, H.-Y. Scalable Solution-Grown High-Germanium-Nanoparticle-Loading Graphene Nanocomposites as HighPerformance Lithium-Ion Battery Electrodes: An Example of a Graphene-Based Platform toward Practical Full-Cell Applications. Chem. Mater. 2014, 26, 2172-2179. [CrossRef]

64. Qin, J.; He, C.; Zhao, N.; Wang, Z.; Shi, C.; Liu, E.-Z.; Li, J. Graphene Networks Anchored with Sn@Graphene as Lithium Ion Battery Anode. ACS Nano 2014, 8, 1728-1738. [CrossRef]

65. Liang, S.; Zhu, X.; Lian, P.; Yang, W.; Wang, H. Superior Cycle Performance of Sn@C/Graphene Nanocomposite as an Anode Material for Lithium-Ion Batteries. J. Solid State Chem. 2011, 184, 1400-1404. [CrossRef]

66. Wang, C.; Li, Y.; Chui, Y.-S.; Wu, Q.-H.; Chen, X.; Zhang, W. Three-Dimensional Sn-Graphene Anode for High-Performance Lithium-Ion Batteries. Nanoscale 2013, 5, 10599. [CrossRef] [PubMed]

67. Kim, H.; Son, Y.; Park, C.; Cho, J.; Choi, H.C. Catalyst-Free Direct Growth of a Single to a Few Layers of Graphene on a Germanium Nanowire for the Anode Material of a Lithium Battery. Angew. Chem. Int. Ed. 2013, 52, 5997-6001. [CrossRef] [PubMed]

68. Wang, H.; Maiyalagan, T.; Wang, X. Review on Recent Progress in Nitrogen-Doped Graphene: Synthesis, Characterization, and Its Potential Applications. ACS Catal. 2012, 2, 781-794. [CrossRef]

69. Lu, Y.; Yu, L.; Lou, X.W. Nanostructured Conversion-Type Anode Materials for Advanced Lithium-Ion Batteries. Chem 2018, 4 972-996. [CrossRef] 
70. Kim, H.; Seo, D.-H.; Kim, S.-W.; Kim, J.; Kang, K. Highly Reversible $\mathrm{Co}_{3} \mathrm{O}_{4}$ / Graphene Hybrid Anode for Lithium Rechargeable Batteries. Carbon 2011, 49, 326-332. [CrossRef]

71. Wu, Z.-S.; Ren, W.; Wen, L.; Gao, L.; Zhao, J.; Chen, Z.; Zhou, G.; Li, F.; Cheng, H.-M. Graphene Anchored with Co ${ }_{3} \mathrm{O}_{4}$ Nanoparticles as Anode of Lithium Ion Batteries with Enhanced Reversible Capacity and Cyclic Performance. ACS Nano 2010, 4, 3187-3194. [CrossRef]

72. Jiang, T.; Bu, F.; Feng, X.; Shakir, I.; Hao, G.; Xu, Y. Porous $\mathrm{Fe}_{2} \mathrm{O}_{3}$ Nanoframeworks Encapsulated within Three-Dimensional Graphene as High-Performance Flexible Anode for Lithium-Ion Battery. ACS Nano 2017, 11, 5140-5147. [CrossRef]

73. Zhou, G.; Wang, D.-W.; Li, F.; Zhang, L.; Li, N.; Wu, Z.-S.; Wen, L.; Lu, G.Q.; Cheng, H.-M. Graphene-Wrapped Fe ${ }_{3} \mathrm{O}_{4}$ Anode Material with Improved Reversible Capacity and Cyclic Stability for Lithium Ion Batteries. Chem. Mater. 2010, 22, 5306-5313. [CrossRef]

74. Zhu, X.; Zhu, Y.; Murali, S.; Stoller, M.D.; Ruoff, R.S. Nanostructured Reduced Graphene Oxide/ $\mathrm{Fe}_{2} \mathrm{O}_{3}$ Composite as a HighPerformance Anode Material for Lithium Ion Batteries. ACS Nano 2011, 5, 3333-3338. [CrossRef]

75. Mai, Y.J.; Shi, S.J.; Zhang, D.; Lu, Y.; Gu, C.D.; Tu, J.P. NiO-Graphene Hybrid as an Anode Material for Lithium Ion Batteries. J. Power Sources 2012, 204, 155-161. [CrossRef]

76. Wang, B.; Wu, X.-L.; Shu, C.-Y.; Guo, Y.-G.; Wang, C.-R. Synthesis of CuO/Graphene Nanocomposite as a High-Performance Anode Material for Lithium-Ion Batteries. J. Mater. Chem. 2010, 20, 10661. [CrossRef]

77. Mai, Y.J.; Wang, X.L.; Xiang, J.Y.; Qiao, Y.Q.; Zhang, D.; Gu, C.D.; Tu, J.P. CuO/Graphene Composite as Anode Materials for Lithium-Ion Batteries. Electrochim. Acta 2011, 56, 2306-2311. [CrossRef]

78. Li, L.; Raji, A.-R.O.; Tour, J.M. Graphene-Wrapped $\mathrm{MnO}_{2}-$ Graphene Nanoribbons as Anode Materials for High-Performance Lithium Ion Batteries. Adv. Mater. 2013, 25, 6298-6302. [CrossRef] [PubMed]

79. Sun, Y.; Hu, X.; Luo, W.; Xia, F.; Huang, Y. Reconstruction of Conformal Nanoscale MnO on Graphene as a High-Capacity and Long-Life Anode Material for Lithium Ion Batteries. Adv. Funct. Mater. 2013, 23, 2436-2444. [CrossRef]

80. Yu, M.; Wang, A.; Wang, Y.; Li, C.; Shi, G. An Alumina Stabilized ZnO-Graphene Anode for Lithium Ion Batteries via Atomic Layer Deposition. Nanoscale 2014, 6, 11419-11424. [CrossRef] [PubMed]

81. Du, Z.; Yin, X.; Zhang, M.; Hao, Q.; Wang, Y.; Wang, T. In Situ Synthesis of $\mathrm{SnO}_{2} /$ Graphene Nanocomposite and Their Application as Anode Material for Lithium Ion Battery. Mater. Lett. 2010, 64, 2076-2079. [CrossRef]

82. Lian, P.; Zhu, X.; Liang, S.; Li, Z.; Yang, W.; Wang, H. High Reversible Capacity of $\mathrm{SnO}_{2} /$ Graphene Nanocomposite as an Anode Material for Lithium-Ion Batteries. Electrochim. Acta 2011, 56, 4532-4539. [CrossRef]

83. Feng, C.; Zhang, L.; Yang, M.; Song, X.; Zhao, H.; Jia, Z.; Sun, K.; Liu, G. One-Pot Synthesis of Copper Sulfide Nanowires/Reduced Graphene Oxide Nanocomposites with Excellent Lithium-Storage Properties as Anode Materials for Lithium-Ion Batteries. ACS Appl. Mater. Interfaces 2015, 7, 15726-15734. [CrossRef]

84. Youn, D.H.; Stauffer, S.K.; Xiao, P.; Park, H.; Nam, Y.; Dolocan, A.; Henkelman, G.; Heller, A.; Mullins, C.B. Simple Synthesis of Nanocrystalline Tin Sulfide/N-Doped Reduced Graphene Oxide Composites as Lithium Ion Battery Anodes. ACS Nano 2016, 10, 10778-10788. [CrossRef] [PubMed]

85. Fei, L.; Lin, Q.; Yuan, B.; Chen, G.; Xie, P.; Li, Y.; Xu, Y.; Deng, S.; Smirnov, S.; Luo, H. Reduced Graphene Oxide Wrapped FeS Nanocomposite for Lithium-Ion Battery Anode with Improved Performance. ACS Appl. Mater. Interfaces 2013, 5, $5330-5335$. [CrossRef] [PubMed]

86. Huang, G.; Chen, T.; Wang, Z.; Chang, K.; Chen, W. Synthesis and Electrochemical Performances of Cobalt Sulfides/Graphene Nanocomposite as Anode Material of Li-Ion Battery. J. Power Sources 2013, 235, 122-128. [CrossRef]

87. Peng, S.; Han, X.; Li, L.; Zhu, Z.; Cheng, F.; Srinivansan, M.; Adams, S.; Ramakrishna, S. Unique Cobalt Sulfide/Reduced Graphene Oxide Composite as an Anode for Sodium-Ion Batteries with Superior Rate Capability and Long Cycling Stability. Small 2016, 12, 1359-1368. [CrossRef]

88. AbdelHamid, A.A.; Yang, X.; Yang, J.; Chen, X.; Ying, J.Y. Graphene-Wrapped Nickel Sulfide Nanoprisms with Improved Performance for Li-Ion Battery Anodes and Supercapacitors. Nano Energy 2016, 26, 425-437. [CrossRef]

89. Mahmood, N.; Zhang, C.; Hou, Y. Nickel Sulfide/Nitrogen-Doped Graphene Composites: Phase-Controlled Synthesis and High Performance Anode Materials for Lithium Ion Batteries. Small 2013, 9, 1321-1328. [CrossRef]

90. Chen, R.; Zhao, T.; Wu, W.; Wu, F.; Li, L.; Qian, J.; Xu, R.; Wu, H.; Albishri, H.M.; Al-Bogami, A.S.; et al. Free-Standing Hierarchically Sandwich-Type Tungsten Disulfide Nanotubes/Graphene Anode for Lithium-Ion Batteries. Nano Lett. 2014, 14, 5899-5904. [CrossRef]

91. Lin, D.; Liu, Y.; Cui, Y. Reviving the Lithium Metal Anode for High-Energy Batteries. Nat. Nanotechnol. 2017, 12, 194-206. [CrossRef]

92. Shi, P.; Zhang, X.; Shen, X.; Zhang, R.; Liu, H.; Zhang, Q. A Review of Composite Lithium Metal Anode for Practical Applications. Adv. Mater. Technol. 2020, 5, 1900806. [CrossRef]

93. Cheng, X.-B.; Zhang, R.; Zhao, C.-Z.; Zhang, Q. Toward Safe Lithium Metal Anode in Rechargeable Batteries: A Review. Chem. Rev. 2017, 117, 10403-10473. [CrossRef]

94. Cheng, X.-B.; Zhang, R.; Zhao, C.-Z.; Wei, F.; Zhang, J.-G.; Zhang, Q. A Review of Solid Electrolyte Interphases on Lithium Metal Anode. Adv. Sci. 2016, 3, 1500213. [CrossRef]

95. Aurbach, D. A Short Review of Failure Mechanisms of Lithium Metal and Lithiated Graphite Anodes in Liquid Electrolyte Solutions. Solid State Ion. 2002, 148, 405-416. [CrossRef] 
96. Zhang, R.; Chen, X.-R.; Chen, X.; Cheng, X.-B.; Zhang, X.-Q.; Yan, C.; Zhang, Q. Lithiophilic Sites in Doped Graphene Guide Uniform Lithium Nucleation for Dendrite-Free Lithium Metal Anodes. Angew. Chem. Int. Ed. 2017, 56, 7764-7768. [CrossRef]

97. Wang, H.; Li, Y.; Li, Y.; Liu, Y.; Lin, D.; Zhu, C.; Chen, G.; Yang, A.; Yan, K.; Chen, H.; et al. Wrinkled Graphene Cages as Hosts for High-Capacity Li Metal Anodes Shown by Cryogenic Electron Microscopy. Nano Lett. 2019, 19, 1326-1335. [CrossRef]

98. Zhao, J.; Zhou, G.; Yan, K.; Xie, J.; Li, Y.; Liao, L.; Jin, Y.; Liu, K.; Hsu, P.-C.; Wang, J.; et al. Air-Stable and Freestanding Lithium Alloy/Graphene Foil as an Alternative to Lithium Metal Anodes. Nat. Nanotechnol. 2017, 12, 993-999. [CrossRef]

99. Cheng, X.-B.; Peng, H.-J.; Huang, J.-Q.; Zhang, R.; Zhao, C.-Z.; Zhang, Q. Dual-Phase Lithium Metal Anode Containing a Polysulfide-Induced Solid Electrolyte Interphase and Nanostructured Graphene Framework for Lithium-Sulfur Batteries. ACS Nano 2015, 9, 6373-6382. [CrossRef]

100. Dong, L.; Nie, L.; Liu, W. Water-Stable Lithium Metal Anodes with Ultrahigh-Rate Capability Enabled by a Hydrophobic Graphene Architecture. Adv. Mater. 2020, 32, 1908494. [CrossRef]

101. Huang, G.; Han, J.; Zhang, F.; Wang, Z.; Kashani, H.; Watanabe, K.; Chen, M. Lithiophilic 3D Nanoporous Nitrogen-Doped Graphene for Dendrite-Free and Ultrahigh-Rate Lithium-Metal Anodes. Adv. Mater. 2019, 31, 1805334. [CrossRef]

102. Lin, D.; Liu, Y.; Liang, Z.; Lee, H.-W.; Sun, J.; Wang, H.; Yan, K.; Xie, J.; Cui, Y. Layered Reduced Graphene Oxide with Nanoscale Interlayer Gaps as a Stable Host for Lithium Metal Anodes. Nat. Nanotechnol. 2016, 11, 626-632. [CrossRef]

103. Liu, S.; Wang, A.; Li, Q.; Wu, J.; Chiou, K.; Huang, J.; Luo, J. Crumpled Graphene Balls Stabilized Dendrite-Free Lithium Metal Anodes. Joule 2018, 2, 184-193. [CrossRef]

104. Mukherjee, R.; Thomas, A.V.; Datta, D.; Singh, E.; Li, J.; Eksik, O.; Shenoy, V.B.; Koratkar, N. Defect-Induced Plating of Lithium Metal within Porous Graphene Networks. Nat. Commun. 2014, 5, 3710. [CrossRef]

105. Pu, J.; Li, J.; Shen, Z.; Zhong, C.; Liu, J.; Ma, H.; Zhu, J.; Zhang, H.; Braun, P.V. Interlayer Lithium Plating in Au Nanoparticles Pillared Reduced Graphene Oxide for Lithium Metal Anodes. Adv. Funct. Mater. 2018, 28, 1804133. [CrossRef]

106. Shi, H.; Zhang, C.J.; Lu, P.; Dong, Y.; Wen, P.; Wu, Z.-S. Conducting and Lithiophilic MXene/Graphene Framework for HighCapacity, Dendrite-Free Lithium-Metal Anodes. ACS Nano 2019, 13, 14308-14318. [CrossRef]

107. Wang, A.; Zhang, X.; Yang, Y.-W.; Huang, J.; Liu, X.; Luo, J. Horizontal Centripetal Plating in the Patterned Voids of Li/Graphene Composites for Stable Lithium-Metal Anodes. Chem 2018, 4, 2192-2200. [CrossRef]

108. Wang, T.; Zhai, P.; Legut, D.; Wang, L.; Liu, X.; Li, B.; Dong, C.; Fan, Y.; Gong, Y.; Zhang, Q. S-Doped Graphene-Regional Nucleation Mechanism for Dendrite-Free Lithium Metal Anodes. Adv. Energy Mater. 2019, 9, 1804000. [CrossRef]

109. Xue, P.; Liu, S.; Shi, X.; Sun, C.; Lai, C.; Zhou, Y.; Sui, D.; Chen, Y.; Liang, J. A Hierarchical Silver-Nanowire-Graphene Host Enabling Ultrahigh Rates and Superior Long-Term Cycling of Lithium-Metal Composite Anodes. Adv. Mater. 2018, 30, 1804165. [CrossRef]

110. Chaitoglou, S.; Spachis, L.; Zisis, G.; Raptis, I.; Papanikolaou, N.; Vavouliotis, A.; Penedo, R.; Fernandes, N.; Dimoulas, A. Layer-by-Layer Assembled Graphene Coatings on Polyurethane Films as He Permeation Barrier. Prog. Org. Coat. 2021, 150, 105984. [CrossRef]

111. Lochala, J.A.; Zhang, H.; Wang, Y.; Okolo, O.; Li, X.; Xiao, J. Practical Challenges in Employing Graphene for Lithium-Ion Batteries and Beyond. Small Methods 2017, 1, 1700099. [CrossRef]

112. Zhang, B.; Yu, Y.; Liu, Y.; Huang, Z.-D.; He, Y.; Kim, J.-K. Percolation Threshold of Graphene Nanosheets as Conductive Additives in Li4Ti5O12 Anodes of Li-Ion Batteries. Nanoscale 2013, 5, 2100. [CrossRef]

113. Jiang, K.-C.; Xin, S.; Lee, J.-S.; Kim, J.; Xiao, X.-L.; Guo, Y.-G. Improved Kinetics of $\mathrm{LiNi}_{1 / 3} \mathrm{Mn}_{1 / 3} \mathrm{Co}_{1 / 3} \mathrm{O}_{2} \mathrm{Cathode} \mathrm{Material}$ through Reduced Graphene Oxide Networks. Phys. Chem. Chem. Phys. 2012, 14, 2934. [CrossRef]

114. Liu, T.; Zhao, L.; Zhu, J.; Wang, B.; Guo, C.; Wang, D. The Composite Electrode of $\mathrm{LiFePO}_{4}$ Cathode Materials Modified with Exfoliated Graphene from Expanded Graphite for High Power Li-Ion Batteries. J. Mater. Chem. A 2014, 2, 2822-2829. [CrossRef]

115. Hsu, T.-H.; Liu, W.-R. Effects of Graphene Nanosheets with Different Lateral Sizes as Conductive Additives on the Electrochemical Performance of $\mathrm{LiNi}_{0.5} \mathrm{Co}_{0.2} \mathrm{Mn}_{0.3} \mathrm{O}_{2}$ Cathode Materials for Li Ion Batteries. Polymers 2020, 12, 1162. [CrossRef]

116. Tian, R.; Alcala, N.; O’Neill, S.J.K.; Horvath, D.V.; Coelho, J.; Griffin, A.J.; Zhang, Y.; Nicolosi, V.; O’Dwyer, C.; Coleman, J.N. Quantifying the Effect of Electronic Conductivity on the Rate Performance of Nanocomposite Battery Electrodes. ACS Appl. Energy Mater. 2020, 3, 2966-2974. [CrossRef]

117. Ju, Z.; Zhang, X.; King, S.T.; Quilty, C.D.; Zhu, Y.; Takeuchi, K.J.; Takeuchi, E.S.; Bock, D.C.; Wang, L.; Marschilok, A.C.; et al. Unveiling the Dimensionality Effect of Conductive Fillers in Thick Battery Electrodes for High-Energy Storage Systems. Appl. Phys. Rev. 2020, 7, 041405. [CrossRef]

118. Sun, D.; Tan, Z.; Tian, X.; Ke, F.; Wu, Y.; Zhang, J. Graphene: A Promising Candidate for Charge Regulation in High-Performance Lithium-Ion Batteries. Nano Res. 2021. [CrossRef]

119. Robertson, A.W.; Allen, C.S.; Wu, Y.A.; He, K.; Olivier, J.; Neethling, J.; Kirkland, A.I.; Warner, J.H. Spatial Control of Defect Creation in Graphene at the Nanoscale. Nat. Commun. 2012, 3, 1144. [CrossRef]

120. Zhong, J.-H.; Zhang, J.; Jin, X.; Liu, J.-Y.; Li, Q.; Li, M.-H.; Cai, W.; Wu, D.-Y.; Zhan, D.; Ren, B. Quantitative Correlation between Defect Density and Heterogeneous Electron Transfer Rate of Single Layer Graphene. J. Am. Chem. Soc. 2014, 136, 16609-16617. [CrossRef]

121. Du, Z.; Ai, W.; Sun, C.; Zou, C.; Zhao, J.; Chen, Y.; Dong, X.; Liu, J.; Sun, G.; Yu, T.; et al. Engineering the Li Storage Properties of Graphene Anodes: Defect Evolution and Pore Structure Regulation. ACS Appl. Mater. Interfaces 2016, 8, 33712-33722. [CrossRef] 
122. Ding, Y.; Jiang, Y.; Xu, F.; Yin, J.; Ren, H.; Zhuo, Q.; Long, Z.; Zhang, P. Preparation of Nano-Structured $\mathrm{LiFePO}_{4} / \mathrm{Graphene}$ Composites by Co-Precipitation Method. Electrochem. Commun. 2010, 12, 10-13. [CrossRef]

123. Wang, L.; Wang, H.; Liu, Z.; Xiao, C.; Dong, S.; Han, P.; Zhang, Z.; Zhang, X.; Bi, C.; Cui, G. A Facile Method of Preparing Mixed Conducting $\mathrm{LiFePO}_{4} /$ Graphene Composites for Lithium-Ion Batteries. Solid State Ion. 2010, 181, 1685-1689. [CrossRef]

124. Su, C.; Bu, X.; Xu, L.; Liu, J.; Zhang, C. A Novel LiFePO $/$ Graphene/Carbon Composite as a Performance-Improved Cathode Material for Lithium-Ion Batteries. Electrochim. Acta 2012, 64, 190-195. [CrossRef]

125. Zhou, X.; Wang, F.; Zhu, Y.; Liu, Z. Graphene Modified $\mathrm{LiFePO}_{4}$ Cathode Materials for High Power Lithium Ion Batteries. J. Mater. Chem. 2011, 21, 3353. [CrossRef]

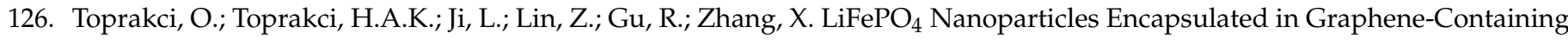
Carbon Nanofibers for Use as Energy Storage Materials. J. Renew. Sustain. Energy 2012, 4, 013121. [CrossRef]

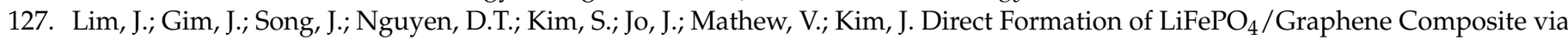
Microwave-Assisted Polyol Process. J. Power Sources 2016, 304, 354-359. [CrossRef]

128. Cai, X.; Lai, L.; Shen, Z.; Lin, J. Graphene and Graphene-Based Composites as Li-Ion Battery Electrode Materials and Their Application in Full Cells. J. Mater. Chem. A 2017, 5, 15423-15446. [CrossRef]

129. Kumar, R.; Sahoo, S.; Joanni, E.; Singh, R.K.; Tan, W.K.; Kar, K.K.; Matsuda, A. Recent Progress in the Synthesis of Graphene and Derived Materials for next Generation Electrodes of High Performance Lithium Ion Batteries. Prog. Energy Combust. Sci. 2019, 75, 100786. [CrossRef]

130. Akbar, S.; Rehan, M.; Liu, H.; Rafique, I.; Akbar, H. A Brief Review on Graphene Applications in Rechargeable Lithium Ion Battery Electrode Materials. Carbon Lett. 2018, 28, 1-8. [CrossRef]

131. Venkateswara Rao, C.; Leela Mohana Reddy, A.; Ishikawa, Y.; Ajayan, P.M. $\mathrm{LiNi}_{1 / 3} \mathrm{Co}_{1 / 3} \mathrm{Mn}_{1 / 3} \mathrm{O}_{2}$-Graphene Composite as a Promising Cathode for Lithium-Ion Batteries. ACS Appl. Mater. Interfaces 2011, 3, 2966-2972. [CrossRef]

132. Wood, M.; Li, J.; Ruther, R.E.; Du, Z.; Self, E.C.; Meyer, H.M.; Daniel, C.; Belharouak, I.; Wood, D.L. Chemical Stability and Long-Term Cell Performance of Low-Cobalt, Ni-Rich Cathodes Prepared by Aqueous Processing for High-Energy Li-Ion Batteries. Energy Storage Mater. 2020, 24, 188-197. [CrossRef]

133. Shim, J.-H.; Kim, C.-Y.; Cho, S.-W.; Missiul, A.; Kim, J.-K.; Ahn, Y.J.; Lee, S. Effects of Heat-Treatment Atmosphere on Electrochemical Performances of Ni-Rich Mixed-Metal Oxide $\left(\mathrm{LiNi}_{0.80} \mathrm{Co}_{0.15} \mathrm{Mn}_{0.05} \mathrm{O}_{2}\right)$ as a Cathode Material for Lithium Ion Battery. Electrochim. Acta 2014, 138, 15-21. [CrossRef]

134. Jan, S.S.; Nurgul, S.; Shi, X.; Xia, H.; Pang, H. Improvement of Electrochemical Performance of $\mathrm{LiNi}_{0.8} \mathrm{Co}_{0.1} \mathrm{Mn}_{0.1} \mathrm{O}_{2} \mathrm{Cathode}$ Material by Graphene Nanosheets Modification. Electrochim. Acta 2014, 149, 86-93. [CrossRef]

135. Park, C.W.; Lee, J.-H.; Seo, J.K.; Jo, W.Y.; Whang, D.; Hwang, S.M.; Kim, Y.-J. Graphene Collage on Ni-Rich Layered Oxide Cathodes for Advanced Lithium-Ion Batteries. Nat. Commun. 2021, 12, 2145. [CrossRef]

136. He, X.; Han, G.; Lou, S.; Du, L.; Xu, X.; Du, C.; Cheng, X.; Zuo, P.; Ma, Y.; Huo, H.; et al. Improved Electrochemical Performance of $\mathrm{LiNi}_{0.8} \mathrm{Co}_{0.15} \mathrm{Al}_{0.05} \mathrm{O}_{2}$ Cathode Material by Coating of Graphene Nanodots. J. Electrochem. Soc. 2019, 166, A1038-A1044. [CrossRef]

137. Yao, F.; Güneş, F.; Ta, H.Q.; Lee, S.M.; Chae, S.J.; Sheem, K.Y.; Cojocaru, C.S.; Xie, S.S.; Lee, Y.H. Diffusion Mechanism of Lithium Ion through Basal Plane of Layered Graphene. J. Am. Chem. Soc. 2012, 134, 8646-8654. [CrossRef]

138. Persson, K.; Sethuraman, V.A.; Hardwick, L.J.; Hinuma, Y.; Meng, Y.S.; van der Ven, A.; Srinivasan, V.; Kostecki, R.; Ceder, G. Lithium Diffusion in Graphitic Carbon. J. Phys. Chem. Lett. 2010, 1, 1176-1180. [CrossRef]

139. Xu, Y.; Lin, Z.; Zhong, X.; Huang, X.; Weiss, N.O.; Huang, Y.; Duan, X. Holey Graphene Frameworks for Highly Efficient Capacitive Energy Storage. Nat. Commun. 2014, 5, 4554. [CrossRef]

140. He, J.; Chen, Y.; Li, P.; Wang, Z.; Qi, F.; Liu, J. Synthesis and Electrochemical Properties of Graphene-Modified LiCo $1 / 3 \mathrm{Ni}$ ${ }_{1 / 3} \mathrm{Mn}_{1 / 3} \mathrm{O}_{2}$ Cathodes for Lithium Ion Batteries. RSC Adv. 2014, 4, 2568-2572. [CrossRef]

141. Wu, F.; Yan, Y.; Wang, R.; Cai, H.; Tong, W.; Tang, H. Synthesis of $\mathrm{LiNi}_{1 / 3} \mathrm{Mn}_{1 / 3} \mathrm{Co}_{1 / 3} \mathrm{O}_{2} @$ graphene for Lithium-Ion Batteries via Self-Assembled Polyelectrolyte Layers. Ceram. Int. 2017, 43, 7668-7673. [CrossRef]

142. Luo, W.; Liu, L.; Li, X.; Yu, J.; Fang, C. Templated Assembly of $\mathrm{LiNi}_{0.8} \mathrm{Co}_{0 \cdot 15} \mathrm{Al}_{0.05} \mathrm{O}_{2} /$ Graphene Nano Composite with High Rate Capability and Long-Term Cyclability for Lithium Ion Battery. J. Alloys Compd. 2019, 810, 151786. [CrossRef]

143. Song, B.; Lai, M.O.; Liu, Z.; Liu, H.; Lu, L. Graphene-Based Surface Modification on Layered Li-Rich Cathode for HighPerformance Li-Ion Batteries. J. Mater. Chem. A 2013, 1, 9954. [CrossRef]

144. Ju, J.-H.; Cho, S.-W.; Hwang, S.-G.; Yun, S.-R.; Lee, Y.; Jeong, H.M.; Hwang, M.-J.; Kim, K.M.; Ryu, K.-S. Electrochemical Performance of $\mathrm{Li}\left[\mathrm{Co}_{0.1} \mathrm{Ni}_{0.15} \mathrm{Li}_{0.2} \mathrm{Mn}_{0.55}\right] \mathrm{O}_{2}$ Modified by Carbons as Cathode Materials. Electrochim. Acta 2011, 56, 8791-8796. [CrossRef]

145. Jiang, K.-C.; Wu, X.-L.; Yin, Y.-X.; Lee, J.-S.; Kim, J.; Guo, Y.-G. Superior Hybrid Cathode Material Containing Lithium-Excess Layered Material and Graphene for Lithium-Ion Batteries. ACS Appl. Mater. Interfaces 2012, 4, 4858-4863. [CrossRef] [PubMed]

146. Manthiram, A.; Fu, Y.; Chung, S.-H.; Zu, C.; Su, Y.-S. Rechargeable Lithium-Sulfur Batteries. Chem. Rev. 2014, 114, 11751-11787. [CrossRef] [PubMed]

147. Manthiram, A.; Fu, Y.; Su, Y.-S. Challenges and Prospects of Lithium-Sulfur Batteries. Acc. Chem. Res. 2013, 46, 1125-1134. [CrossRef]

148. Papandrea, B.; Xu, X.; Xu, Y.; Chen, C.-Y.; Lin, Z.; Wang, G.; Luo, Y.; Liu, M.; Huang, Y.; Mai, L.; et al. Three-Dimensional Graphene Framework with Ultra-High Sulfur Content for a Robust Lithium-Sulfur Battery. Nano Res. 2016, 9, 240-248. [CrossRef] 
149. Chong, W.G.; Huang, J.-Q.; Xu, Z.-L.; Qin, X.; Wang, X.; Kim, J.-K. Lithium-Sulfur Battery Cable Made from Ultralight, Flexible Graphene/Carbon Nanotube/Sulfur Composite Fibers. Adv. Funct. Mater. 2017, 27, 1604815. [CrossRef]

150. Huang, J.-Q.; Zhuang, T.-Z.; Zhang, Q.; Peng, H.-J.; Chen, C.-M.; Wei, F. Permselective Graphene Oxide Membrane for Highly Stable and Anti-Self-Discharge Lithium-Sulfur Batteries. ACS Nano 2015, 9, 3002-3011. [CrossRef]

151. Li, H.; Yang, X.; Wang, X.; Liu, M.; Ye, F.; Wang, J.; Qiu, Y.; Li, W.; Zhang, Y. Dense Integration of Graphene and Sulfur through the Soft Approach for Compact Lithium/Sulfur Battery Cathode. Nano Energy 2015, 12, 468-475. [CrossRef]

152. Tang, C.; Li, B.-Q.; Zhang, Q.; Zhu, L.; Wang, H.-F.; Shi, J.-L.; Wei, F. CaO-Templated Growth of Hierarchical Porous Graphene for High-Power Lithium-Sulfur Battery Applications. Adv. Funct. Mater. 2016, 26, 577-585. [CrossRef]

153. Wang, C.; Wang, X.; Wang, Y.; Chen, J.; Zhou, H.; Huang, Y. Macroporous Free-Standing Nano-Sulfur/Reduced Graphene Oxide Paper as Stable Cathode for Lithium-Sulfur Battery. Nano Energy 2015, 11, 678-686. [CrossRef]

154. Wang, C.; Wang, X.; Yang, Y.; Kushima, A.; Chen, J.; Huang, Y.; Li, J. Slurryless Li 2 S/Reduced Graphene Oxide Cathode Paper for High-Performance Lithium Sulfur Battery. Nano Lett. 2015, 15, 1796-1802. [CrossRef]

155. Wang, H.; Yang, Y.; Liang, Y.; Robinson, J.T.; Li, Y.; Jackson, A.; Cui, Y.; Dai, H. Graphene-Wrapped Sulfur Particles as a Rechargeable Lithium-Sulfur Battery Cathode Material with High Capacity and Cycling Stability. Nano Lett. 2011, 11, $2644-2647$. [CrossRef]

156. Yang, X.; Zhang, L.; Zhang, F.; Huang, Y.; Chen, Y. Sulfur-Infiltrated Graphene-Based Layered Porous Carbon Cathodes for High-Performance Lithium-Sulfur Batteries. ACS Nano 2014, 8, 5208-5215. [CrossRef]

157. Zhang, Z.; Kong, L.-L.; Liu, S.; Li, G.-R.; Gao, X.-P. A High-Efficiency Sulfur/Carbon Composite Based on 3D Graphene Nanosheet@Carbon Nanotube Matrix as Cathode for Lithium-Sulfur Battery. Adv. Energy Mater. 2017, 7, 1602543. [CrossRef]

158. Zhou, G.; Yin, L.-C.; Wang, D.-W.; Li, L.; Pei, S.; Gentle, I.R.; Li, F.; Cheng, H.-M. Fibrous Hybrid of Graphene and Sulfur Nanocrystals for High-Performance Lithium-Sulfur Batteries. ACS Nano 2013, 7, 5367-5375. [CrossRef] [PubMed]

159. Nestler, T.; Schmid, R.; Münchgesang, W.; Bazhenov, V.; Schilm, J.; Leisegang, T.; Meyer, D.C. Separators-Technology Review: Ceramic Based Separators for Secondary Batteries. AIP Conf. Proc. 2014, 1597, 155-184. [CrossRef]

160. Chen, X.; Chen, S.; Lin, Y.; Wu, K.; Lu, S. Multi-Functional Ceramic-Coated Separator for Lithium-Ion Batteries Safety Tolerance Improvement. Ceram. Int. 2020, 46, 24689-24697. [CrossRef]

161. Lei, T.; Chen, W.; Lv, W.; Huang, J.; Zhu, J.; Chu, J.; Yan, C.; Wu, C.; Yan, Y.; He, W.; et al. Inhibiting Polysulfide Shuttling with a Graphene Composite Separator for Highly Robust Lithium-Sulfur Batteries. Joule 2018, 2, 2091-2104. [CrossRef]

162. Lin, W.; Chen, Y.; Li, P.; He, J.; Zhao, Y.; Wang, Z.; Liu, J.; Qi, F.; Zheng, B.; Zhou, J.; et al. Enhanced Performance of Lithium Sulfur Battery with a Reduced Graphene Oxide Coating Separator. J. Electrochem. Soc. 2015, 162, A1624-A1629. [CrossRef]

163. Jiang, Y.; Chen, F.; Gao, Y.; Wang, Y.; Wang, S.; Gao, Q.; Jiao, Z.; Zhao, B.; Chen, Z. Inhibiting the Shuttle Effect of Li-S Battery with a Graphene Oxide Coating Separator: Performance Improvement and Mechanism Study. J. Power Sources 2017, 342, 929-938. [CrossRef]

164. Peng, H.; Wang, D.; Huang, J.; Cheng, X.; Yuan, Z.; Wei, F.; Zhang, Q. Janus Separator of Polypropylene-Supported Cellular Graphene Framework for Sulfur Cathodes with High Utilization in Lithium-Sulfur Batteries. Adv. Sci. 2016, 3, 1500268. [CrossRef] [PubMed]

165. Shin, W.-K.; Kannan, A.G.; Kim, D.-W. Effective Suppression of Dendritic Lithium Growth Using an Ultrathin Coating of Nitrogen and Sulfur Codoped Graphene Nanosheets on Polymer Separator for Lithium Metal Batteries. ACS Appl. Mater. Interfaces 2015, 7 , 23700-23707. [CrossRef]

166. Song, X.; Wang, S.; Chen, G.; Gao, T.; Bao, Y.; Ding, L.-X.; Wang, H. Fe-N-Doped Carbon Nanofiber and Graphene Modified Separator for Lithium-Sulfur Batteries. Chem. Eng. J. 2018, 333, 564-571. [CrossRef]

167. Zhai, P.-Y.; Peng, H.-J.; Cheng, X.-B.; Zhu, L.; Huang, J.-Q.; Zhu, W.; Zhang, Q. Scaled-up Fabrication of Porous-GrapheneModified Separators for High-Capacity Lithium-Sulfur Batteries. Energy Storage Mater. 2017, 7, 56-63. [CrossRef]

168. Zhao, Y.; Liu, M.; Lv, W.; He, Y.-B.; Wang, C.; Yun, Q.; Li, B.; Kang, F.; Yang, Q.-H. Dense Coating of Li4Ti5O12 and Graphene Mixture on the Separator to Produce Long Cycle Life of Lithium-Sulfur Battery. Nano Energy 2016, 30, 1-8. [CrossRef]

169. Zhou, G.; Li, L.; Wang, D.-W.; Shan, X.; Pei, S.; Li, F.; Cheng, H.-M. A Flexible Sulfur-Graphene-Polypropylene Separator Integrated Electrode for Advanced Li-S Batteries. Adv. Mater. 2015, 27, 641-647. [CrossRef] [PubMed]

170. Zhu, J.; Chen, C.; Lu, Y.; Zang, J.; Jiang, M.; Kim, D.; Zhang, X. Highly Porous Polyacrylonitrile/Graphene Oxide Membrane Separator Exhibiting Excellent Anti-Self-Discharge Feature for High-Performance Lithium-Sulfur Batteries. Carbon 2016, 101, 272-280. [CrossRef]

171. Zhuang, T.-Z.; Huang, J.-Q.; Peng, H.-J.; He, L.-Y.; Cheng, X.-B.; Chen, C.-M.; Zhang, Q. Rational Integration of Polypropylene/Graphene Oxide/Nafion as Ternary-Layered Separator to Retard the Shuttle of Polysulfides for Lithium-Sulfur Batteries. Small 2016, 12, 381-389. [CrossRef] [PubMed]

172. Su, Y.-S.; Manthiram, A. Lithium-Sulphur Batteries with a Microporous Carbon Paper as a Bifunctional Interlayer. Nat. Commun 2012, 3, 1166. [CrossRef]

173. Su, Y.-S.; Manthiram, A. A New Approach to Improve Cycle Performance of Rechargeable Lithium-Sulfur Batteries by Inserting a Free-Standing MWCNT Interlayer. Chem. Commun. 2012, 48, 8817. [CrossRef]

174. Chang, C.-H.; Chung, S.-H.; Manthiram, A. Ultra-Lightweight PANiNF/MWCNT-Functionalized Separators with Synergistic Suppression of Polysulfide Migration for Li-S Batteries with Pure Sulfur Cathodes. J. Mater. Chem. A 2015, 3, 18829-18834. [CrossRef] 
175. Chang, C.-H.; Chung, S.-H.; Manthiram, A. Effective Stabilization of a High-Loading Sulfur Cathode and a Lithium-Metal Anode in Li-S Batteries Utilizing SWCNT-Modulated Separators. Small 2016, 12, 174-179. [CrossRef] [PubMed]

176. Chung, S.-H.; Manthiram, A. High-Performance Li-S Batteries with an Ultra-Lightweight MWCNT-Coated Separator. J. Phys. Chem. Lett. 2014, 5, 1978-1983. [CrossRef]

177. Wang, M.; Tang, M.; Chen, S.; Ci, H.; Wang, K.; Shi, L.; Lin, L.; Ren, H.; Shan, J.; Gao, P.; et al. Graphene-Armored Aluminum Foil with Enhanced Anticorrosion Performance as Current Collectors for Lithium-Ion Battery. Adv. Mater. 2017, $29,1703882$. [CrossRef] [PubMed]

178. Zhang, S.; Ding, M.S.; Jow, T.R. Self-Discharge of $\mathrm{Li} / \mathrm{Li}_{x} \mathrm{Mn}_{2} \mathrm{O}_{4}$ Batteries in Relation to Corrosion of Aluminum Cathode Substrates. J. Power Sources 2001, 102, 16-20. [CrossRef]

179. Myung, S.-T.; Hitoshi, Y.; Sun, Y.-K. Electrochemical Behavior and Passivation of Current Collectors in Lithium-Ion Batteries. J. Mater. Chem. 2011, 21, 9891. [CrossRef]

180. Ma, T.; Xu, G.; Li, Y.; Wang, L.; He, X.; Zheng, J.; Engelhard, M.H.; Zapol, P.; Curtiss, L.A.; Jorne, J.; et al. Revisiting the Corrosion of Aluminum Current Collector in Lithium-Ion Batteries. J. Phys. Chem. Lett. 2017, 8, 1072-1077. [CrossRef] [PubMed]

181. Zhang, G.; Lin, K.; Qin, X.; Zhang, L.; Li, T.; Lv, F.; Xia, Y.; Han, W.; Kang, F.; Li, B. Electrosprayed Robust Graphene Layer Constructing Ultrastable Electrode Interface for High-Voltage Lithium-Ion Batteries. ACS Appl. Mater. Interfaces 2020, 12, 37034-37046. [CrossRef]

182. Kim, S.Y.; Song, Y.I.; Wee, J.-H.; Kim, C.H.; Ahn, B.W.; Lee, J.W.; Shu, S.J.; Terrones, M.; Kim, Y.A.; Yang, C.-M. Few-Layer Graphene Coated Current Collectors for Safe and Powerful Lithium Ion Batteries. Carbon 2019, 153, 495-503. [CrossRef]

183. Richard Prabakar, S.J.; Hwang, Y.-H.; Bae, E.G.; Lee, D.K.; Pyo, M. Graphene Oxide as a Corrosion Inhibitor for the Aluminum Current Collector in Lithium Ion Batteries. Carbon 2013, 52, 128-136. [CrossRef]

184. Hu, Y.; Li, X.; Wang, J.; Li, R.; Sun, X. Free-Standing Graphene-Carbon Nanotube Hybrid Papers Used as Current Collector and Binder Free Anodes for Lithium Ion Batteries. J. Power Sources 2013, 237, 41-46. [CrossRef]

185. Wang, L.; He, X.; Li, J.; Gao, J.; Fang, M.; Tian, G.; Wang, J.; Fan, S. Graphene-Coated Plastic Film as Current Collector for Lithium/Sulfur Batteries. J. Power Sources 2013, 239, 623-627. [CrossRef] 